Universidade de São Paulo

Faculdade de Medicina de Ribeirão Preto

Departamento de Genética

"Efeitos da inibição das quinases ROCK no potencial invasivo de linhagens celulares de sarcoma de Ewing"

Gabriela Maciel Oieira 
Universidade de São Paulo

Faculdade de Medicina de Ribeirão Preto

Departamento de Genética

\title{
"Efeitos da inibição das quinases ROCK no potencial invasivo de linhagens celulares de sarcoma de Ewing"
}

\author{
Gabriela Maciel Oieira \\ Dissertação apresentada ao Departamento de Genética da \\ Faculdade de Medicina de Ribeirão Preto da \\ Universidade de São Paulo, como parte das exigências para a \\ obtenção do título de Mestre em Ciências Biológicas - Genética.
}

Orientador: Profo. Dr. Luiz Gonzaga Tone 
Autorizo a reprodução e divulgação total ou parcial deste trabalho, por qualquer meio convencional ou eletrônico, para fins de estudo ou pesquisa, desde que citada a fonte.

Vieira, Gabriela Maciel

Efeitos da inibição das quinases ROCK no potencial invasivo de linhagens celulares de sarcoma de Ewing. Ribeirão Preto, 2016. 64f.

Dissertação de mestrado apresentada à Faculdade de Medicina de Ribeirão Preto/USP.

Área de concentração: Genética

Orientador: Tone, Luiz Gonzaga

1. Sarcoma de Ewing. 2. ROCK. 3. GSK429286. 4.SR3677. 5. Hidroxifasudil. 


\section{Apoio e Suporte Financeiro}

Este trabalho foi realizado com o apoio financeiro das seguintes entidades e instituições:

- Fundação de Amparo à Pesquisa do Estado de São Paulo - FAPESP (Processo n 2014/07118-0 e processo no 2014/03877-3);

- Conselho Nacional de Desenvolvimento Científico e Tecnológico CNPq;

- Faculdade de Medicina de Ribeirão Preto - FMRP/USP; 
FOLHA DE APROVAÇÃO

Gabriela Shaciel O)ieira

\section{"Efeitos da inibição das quinases ROCK no potencial invasivo de linhagens celulares de sarcoma de Ewing"}

Dissertação apresentada ao Departamento de Genética da Faculdade de Medicina de Ribeirão Preto da Universidade de São Paulo, como parte das exigências para a obtenção do título de Mestre em Ciências Biológicas - Genética.

Área de Concentração: Genética

Data da defesa:

Aprovado em:

BANCA EXAMINADORA

Prof.Dr.

Instituição: Assinatura:

Prof. Dr. Instituição: Assinatura:

Prof. Dr. Instituição: Assinatura: 
Dedica este wabalho aos meus pais Plodoaldo e Candra, que me ensinaram ser uma pessoa forte e nunca desistir dos meus sonhos. 


\section{AGRADECIMENTOS}

Agradeço primeiramente a Deus, por permitir que eu chegasse até aqui e me dar forças todos os dias para continuar.

Ao Prof. Dr. Luiz Gonzaga Tone, meu orientador, pela oportunidade, confiança e apoio para que eu pudesse realizar esse trabalho.

A Profa Dra María Sol Brassesco Annichini, por ter me acolhido desde o início, permitindo que várias portas fossem abertas para mim, por ter confiado em mim para executar este trabalho, me apoiado, auxiliado e ensinado muitas das coisas que sei hoje.

À Fundação de Apoio do Estado de São Paulo (FAPESP) e ao Conselho Nacional de Pesquisa (CNPq) pela concessão da bolsa de Mestrado e apoio financeiro.

Ao serviço de Ortopedia Oncológica HC-FMRP do Departamento de Biomecânica, Medicina e Reabilitação do Aparelho Locomotor da FMRP-USP, por auxiliar na coleta das amostras tumorais aqui analisadas.

Às técnicas do laboratório de Citogenética do Departamento de Puericultura e Pediatria, Sônia Scandusi, e Lucimar Fernandes pelo apoio e convivência.

Ao Departamento de Genética da Faculdade de Medicina de Ribeirão Preto da Universidade de São Paulo, as secretárias Susie Adriana Penha Nalon, Silvia Sant'anna Consiglieri e a secretária do Laboratório de Puericultura e Pediatria Evelize Visconte, pela ajuda e apoio prestados sempre.

Ao Prof. Dr. Wilson Araújo da Silva Junior, chefe do Departamento de Genética da FMRP/USP, a Profa. Dra. Silvana Giuliatiti coordenadora da Pós-graduação do Departamento de Genética da FMRP/USP, e ao Prof. Dr. Ademilson Espencer E. Soares, excoordenador da Pós-graduação do Departamento de Genética da FMRP/USP.

Aos Prof. Dr. Carlos Alberto Scridelli, Prof. Dr. Edgard Engel, Prof. Dr. Rodrigo Tocantins Calado, Prof. Dr. Rodrigo Panepucci por toda ajuda e discussões científicas. 
As amigas e colegas de laboratório Lara Alberici Delsin, a Karina Bezerra Salomão e a Gabriela Molinari Roberto pela paciência, dedicação e amizade, por nunca medirem esforços para me ajudar e por me ensinarem quase tudo que sei hoje no laboratório.

Aos queridos Mirella Baroni e Gustavo Alencastro Veiga Cruzeiro pela incrível amizade, pelo apoio científico e pessoal, por terem se tornado tão importantes para mim desde o início e por sempre estarem por perto quando eu preciso.

Aos amigos Lenisa Geron, Rodrigo Hakime, Guilherme Vargas, Marcela Oliveria da Silva, Carolina Alvez, Camilla Rodrigues, Pâmela Viani de Andrade, Mariana Ruckert, pelo apoio e companheirismo dentro e fora do laboratório, por todas as risadas e momentos bons que passamos juntos.

A biologista do laboratório Rosane Queiroz por toda ajuda, apoio e paciência durante os experimentos e pela convivência dentro do laboratório.

A todos os amigos do laboratório Vanessa, Veridiana, Kleiton, Régia, Augusto, Daniel, Paola, Giovanna, Caio, pela amizade, apoio e ajuda no meu aprendizado dentro do laboratório.

Às amigas Maritza Salas e Diana Ribeiro por terem se tornado minha família em Ribeirão Preto e dividirem comigo todos os momentos, sejam eles bons ou ruins.

Aos demais amigos de Ribeirão Preto por terem me ajudado a tornar aqui o meu segundo lar e aos amigos de Cascavel por entenderem minha ausência e estarem perto no coração, mesmo que longe fisicamente.

À minha família, minha mãe Sandra Mara Maciel Vieira, meu pai Clodoaldo Gonçalves Vieira e meu irmão Lucas Maciel Vieira, por terem me tornado a pessoa que sou hoje, me ensinado tudo o que sei, me apoiado mesmo nos momentos mais difíceis e aguentarem a saudade diária. Vocês são meu porto seguro e meu motivo para vencer todos os dias!

A todos que de alguma forma, contribuíram para que eu realizasse este trabalho, muito obrigada! 


\section{RESUMO}

VIEIRA, G. M. "Efeitos da inibição das quinases ROCK no potencial invasivo de linhagens celulares de sarcoma de Ewing". 2016, 64f. Dissertação de Mestrado - Faculdade de Medicina de Ribeirão Preto, Universidade de São Paulo, Ribeirão Preto, SP, Brasil.

O sarcoma de Ewing (SE) é um tumor caracterizado por possuir células indiferenciadas, de origem neuroepitelial. É o segundo tumor ósseo maligno mais comum em crianças e adolescentes. $O$ tratamento consiste na aplicação de quimioterapia neoadjuvante, seguida da cirurgia e a quimioterapia adjuvante ou radioterapia. Contudo, a disseminação deste tumor é muito intensa, e mesmo em pacientes onde a metástase não ocorreu, podem haver células tumorais circulantes. Além disso, a sobrevida de 5 anos que cerca de $70 \%$ dos pacientes que não apresentam metástase no momento do diagnóstico atingem, cai para $25 \%$ nos pacientes que apresentam metástase. A migração e invasão celular dos tecidos vizinhos e vasos sanguíneos, a adesão celular e a proliferação são processos essenciais para que a metástase tumoral aconteça. Dentre as reguladoras da mobilidade, adesão celular e proliferação estão as GTPases da família Rho, que possuem entre suas quinases efetoras, ROCK1 e ROCK2. Assim, as proteínas ROCK induzem inúmeras respostas celulares que envolvem a regulação de muitas proteínas associadas ao citoesqueleto. Estudos evidenciam que respostas sinalizadas por ROCK agravam fenótipos associados ao câncer e outras doenças. $O$ presente trabalho teve como objetivo verificar a expressão dos genes ROCK1 e ROCK2 em amostras tumorais e linhagens celulares de SE, e os efeitos in vitro da inibição farmacológica de ambas as quinases. $O$ estudo da expressão gênica de ROCK1 e ROCK2 em amostras de pacientes com SE ( $\mathrm{n}=18)$ revelaram uma hipoexpressão de ambos genes, tanto nas amostras de pacientes com SE quanto nas linhagens celulares SK-ES-1 e RD-ES. Não foi encontrada nenhuma relação das expressões gênicas com os dados clínicos. Contudo, a presença do gene de fusão EWS-FLI1 parece estar associada com menor expressão de ROCK1. Verificou-se que a proliferação celular, a capacidade clonogênica e o ciclo celular não se alteraram significativamente nas linhagens celulares de SE após os diferentes tratamentos com as drogas GSK429286 (inibidor de ROCK1), SR3677 (inibidor de ROCK2) e Hidroxifasudil (pan-inibidor). Porém, apesar de não significativo, observou-se um tênue aumento na migração e invasão celular após o tratamento com as drogas. Nossos dados indicam que ROCK1 e ROCK2 podem possuir um papel na tumorigênese do SE, e ainda estar relacionadas com os mecanismos de migração e invasão celular, processos importantes para a metástase tumoral.

Palavras-chave: Sarcoma de Ewing, ROCK, GSK429286, SR3677, Hidroxifasudil. 


\begin{abstract}
VIEIRA, G. M. "Effects of ROCK kinases inhibition on the invasive potential of Ewing sarcoma cell lines". 2016, 64f. Master's degree dissertation - School of Medicine of Ribeirão Preto, University of São Paulo, Ribeirão Preto, SP, Brazil.

Ewing's sarcoma (ES) is characterized by undifferentiated cells of neuroepithelial origin. It is the second most common malignant bone tumor in children and adolescents. Standard treatment consists of preoperative chemotherapy, followed by surgery and postoperative chemotherapy and/or radiotherapy. However, the spread of the tumor is very high and even in patients where the metastasis has not occurred, there may be circulating tumor cells. Furthermore, the 5-year survival which about $70 \%$ of patients without metastases at diagnosis achieve, falls to $25 \%$ in patients with metastases. Migration and invasion into adjacent tissues and blood vessels, cell adhesion and proliferation are essential for tumor metastasis to occur. Among the regulators of the processes are the Rho family of GTPases, which have as their effector kinases, ROCK1 and ROCK2. Thus, ROCK induce numerous cellular responses involving the regulation of many proteins associated with the cytoskeleton. Studies show that responses regulated by ROCK aggravate phenotypes associated with cancer and other diseases. This study aimed to verify the expression of ROCK1 and ROCK2 genes in ES tumor samples and to evaluate the effects of their pharmacological inhibition in vitro. Gene expression analysis showed lower expression of ROCK in both, patient samples $(n=18)$ and the SK-ES1 and RD-ES cell lines. There was no relation of gene expression with clinical data. Nonetheless, the presence of EWS-FLI1 fusion appears to be associated with lower expression of ROCK1. Cell proliferation, clonogenic capacity and the cell cycle were not affected after different treatments with GSK429286 (ROCK1 inhibitor), SR3677 (ROCK2 inhibitor) and Hydroxyfasudil (pan-inhibitor). However, although not significant, there was a tenuous increase in cell migration and invasion following treatment with the drugs. Our data suggest that ROCK1 and ROCK2 might have a role in ES tumorigenesis and may be related im part to migration and invasion cell mechanisms, important processes for tumor metastasis.
\end{abstract}

Keywords: Ewing's Sarcoma, ROCK, GSK429286, SR3677, Hydroxyfasudil. 


\section{LISTA DE FIGURAS}

Figura 1: A) Migração amebóide, guiada pela reestruturação e contração de filamentos de actomiosina. B) Migração menquimal, envolvendo a degradação da matriz extracelular [adaptado de Narumiya et al., (2009) por M.S. Brassesco]. .20

Figura 2: A) Domínios estruturais das proteínas ROCK1 e ROCK2; Homodímeros de proteínas ROCK demonstrando sua forma inativa (B) e sua forma ativa (C) após ligação de Rho-GTP [adaptado de Morgan-Fisher et al., (2013) por M. S. Brassesco].

Figura 3: Sinalização da via das proteínas ROCK (Adaptado de Feng et al., 2015). .22

Figura 4: Gel de agarose $2 \%$ mostrando os pacientes positivos para o gene de fusão EWSFLI1. Os pacientes não identificados não foram diagnosticados com SE. A diferença nos tamanhos das bandas corresponde a diferentes pontos de quebra entre os pacientes. $\mathrm{CT}=$ controle positivo; $M=$ marcador de peso molecular (ladder de 1 kb Invitrogen).

Figura 5: Expressão relativa do gene ROCK1 em amostras de pacientes com SE, em amostras de osso não neoplásico, nas linhagens primárias de osteoblasto e nas linhagens celulares SKES-1 e RD-ES. As chaves representam diferença significativa entre os grupos analisados $(p \leq 0,05)$

Figura 6: Expressão relativa do gene ROCK2 em amostras de pacientes com SE, em amostras de osso normal, nas linhagens de osteoblasto e nas linhagens celulares SK-ES-1 e RD-ES. As chaves representam diferença significativa entre os grupos analisados $(p \leq 0,05)$.......

Figura 7: Expressão relativa dos genes ROCK1 e ROCK2 em amostras de pacientes com $\mathrm{SE}$ 36

Figura 8: Expressão relativa do gene ROCK1 em pacientes negativos e positivos para o gene de fusão EWS-FLI1.

Figura 9: Curvas de Sobrevida Global (SG) e Sobrevida Livre de Eventos (SLE) e sua relação com níveis de expressão de ROCK1 (Figuras A e C) e ROCK2 (Figuras B e D). Os pacientes foram divididos em dois grupos: com expressões acima e abaixo da mediana.

Figura 10: Análise da proliferação celular após o tratamento das linhagens SK-ES-1 e RD-ES com as drogas GSK429286 (Figuras A e B), SR3677 (Figuras C e D) e Hidroxifasudil (Figuras E e F), nos tempos de tratamento de $24,48,72$ e $96 \mathrm{~h}$

Figura 11: Análise da capacidade clonogênica das linhagens SK-ES-1 (Figura A) e RD-ES (Figura B) após $48 \mathrm{~h}$ de tratamento com as drogas GSK429286, SR3677 e Hidroxifasudi.

Figura 12: Análise da capacidade de migração da linhagem SK-ES-1 por meio de wound healing assay após $24 \mathrm{~h}$ de tratamento com as diferentes concentrações das drogas GSK429286 (Figura A), SR3677 (Figura B) e Hidroxifasudil (Figura C). O gráfico representa os 
valores de taxa de migração relativa mostrando a média e o desvio padrão em cada tratamento (Figura D).....

Figura 13: Análise da capacidade invasiva em matrigel da linhagem celular SK-ES-1 após $24 \mathrm{~h}$ de tratamento com as diferentes concentrações das drogas GSK429286 (Figura A), SR3677 (Figura B) e Hidroxifasudil (Figura C). O gráfico representa os valores de invasão celular relativa mostrando a média e o desvio padrão em cada tratamento (Figura D)

Figura 14: Análise do ciclo celular na linhagem celular SK-ES-1 após o tratamento de $24 \mathrm{~h}$ com as diferentes concentrações das drogas GSK429286 (Figura A), SR3677 (Figura B) e Hidroxifasudil (Figura C).

Figura 15: Análise do ciclo celular na linhagem celular RD-ES após o tratamento de $24 \mathrm{~h}$ com as diferentes concentrações das drogas GSK429286 (Figura A), SR3677 (Figura B) e Hidroxifasudil (Figura C). 


\section{LISTA DE TABELAS}

Tabela I. Dados clínicos referentes à idade, sexo, tamanho do tumor, huvos, metástase, localização e status dos pacientes incluídos no estudo. 


\section{LISTA DE SIGLAS}

\begin{tabular}{ll} 
ACTB & Beta-actina \\
CDNA & DNA Complementar \\
CO $_{2}$ & Dióxido de Carbono \\
DNA & Ácido Desoxirribonucleico \\
DMSO & Dimetilsulfóxido \\
dNTP & Dinucleotídeo Trifosfatado \\
elF5A & Eukaryotic translation initiation factor 5A \\
FMRP & Faculdade de Medicina de Ribeirão Preto \\
FTE & Família de Tumores de Ewing \\
GSK429286 & Droga sintética inibidora específica de ROCK1 \\
GTPases & Guanosina Trifosfatases \\
GUSB & Glucoronidase Beta \\
HC & Hospital das Clínicas \\
IC 50 & Concentração Inibitória para 50\% das Células \\
INCA & Instituto Nacional do Câncer \\
McCoy's & Solução Nutritiva para o Cultivo Celular \\
MgCL 2 & Cloreto de Magnésio \\
MRC-5 & Linahgem Celular de Fibroblasto \\
mRNA & Ácido Ribonucléico Mensageiro \\
PBS & Tampão Salina Fosfato \\
PCR & Reação em Cadeia da Polimerase \\
RD-ES & Linhagem Celular de Sarcoma de Ewing \\
RNA & Ácido ribonucleico \\
ROCK1 & Rho-associated coiled-coil protein kinase 1 \\
ROCK2 & Rho-associated coiled-coil protein kinase 2 \\
RPMI & Solução Nutritiva para o Cultivo Celular \\
RT-qPCR & Reação em Cadeia da Polimerase Quantitativa em Tempo Real \\
SBF & Soro Bovino Fetal \\
SE & Sarcoma de Ewing \\
SG & Sobrevida Global \\
siRNA & Small Interfering RNA \\
SK-ES-1 & Linhagem Celular de Sarcoma de Ewing \\
SLE & Sobrevida Livre de Eventos \\
SPSS & Statistical Package for the Social Sciences \\
SR3677 & Droga sintética inibidora específica de ROCK2 \\
UFRJ & Universidade Federal do Rio de Janeiro \\
USP & Universidade de São Paulo \\
UV & Ultravioleta \\
& Droga sintética inibidora de ROCK \\
\hline T2 &
\end{tabular}




\section{LISTA DE SÍMBOLOS}

$\begin{array}{ll}{ }^{\circ} \mathrm{C} & \text { Graus Celsius } \\ \mathrm{cm}^{3} & \text { Centímetros cúbicos } \\ \mathrm{h} & \text { Horas } \\ \mathrm{KDa} & \text { Quilo Dalton } \\ \mathrm{Kb} & \text { Quilobases } \\ \mathrm{L} & \text { Litro } \\ \mathrm{mg} & \text { Miligrama } \\ \mathrm{mL} & \text { Mililitro } \\ \mathrm{nm} & \text { Nanômetro } \\ \mathrm{nM} & \text { Namomolar } \\ \mu \mathrm{L} & \text { Microlitro } \\ \mu \mathrm{M} & \text { Micromolar } \\ \mu \mathrm{m} & \text { Micrômetro } \\ \% & \text { Porcentagem }\end{array}$




\section{SUMÁRIO}

Introdução.

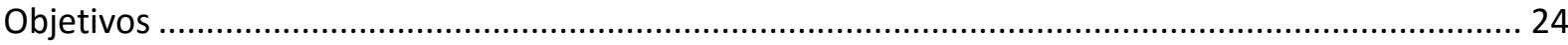

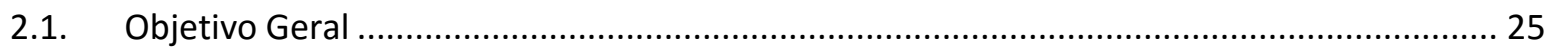

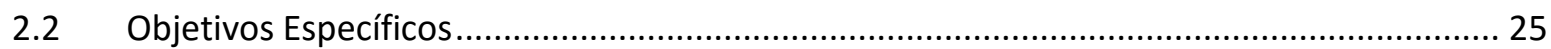

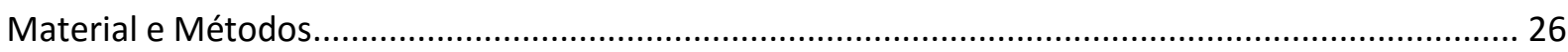

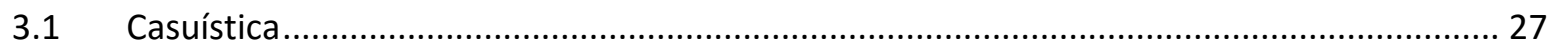

3.2 Linhagens Celulares e Condições de Cultura...................................................... 27

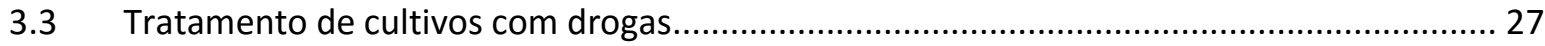

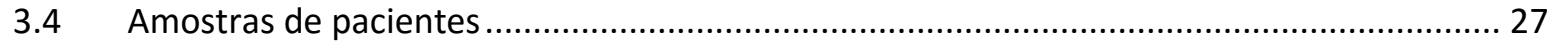

Extração de RNA, qRT-PCR e PCR convencional ....................................................... 28

Ensaio de Proliferação Celular........................................................................... 28

Ensaio de Capacidade Clonogênica ...................................................................... 29

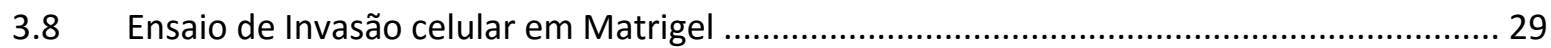

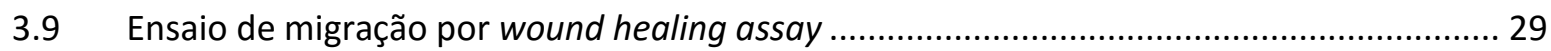

Avaliação do Ciclo Celular .............................................................................. 30

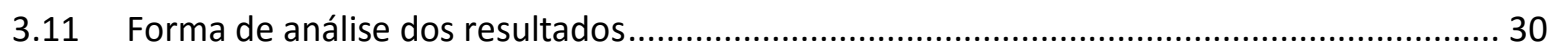

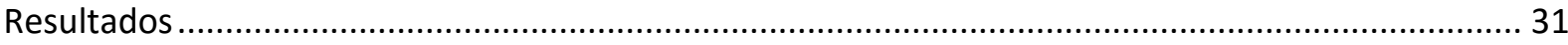

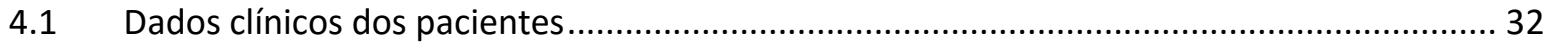

4.2 Expressão dos genes ROCK1 e ROCK2 e relação com dados clínicos .................................. 33

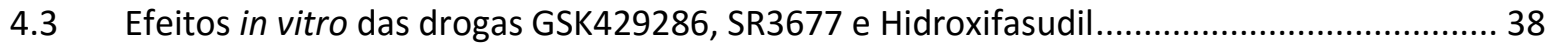

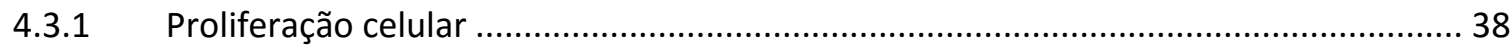

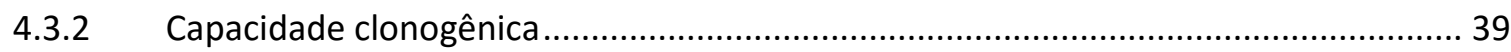

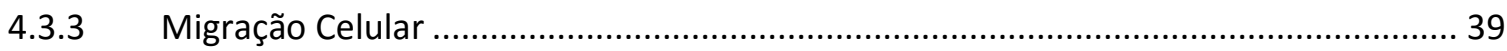

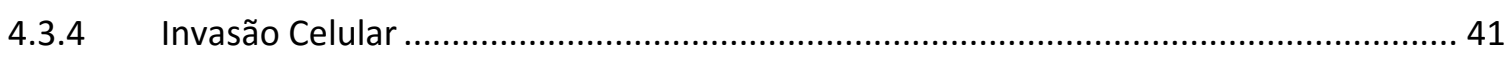

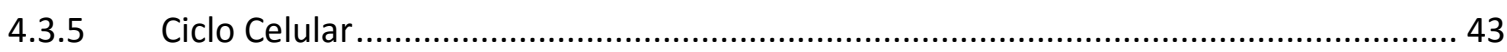

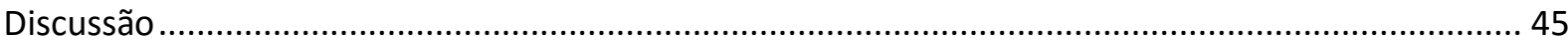

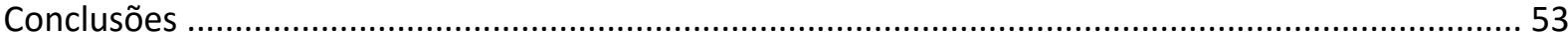

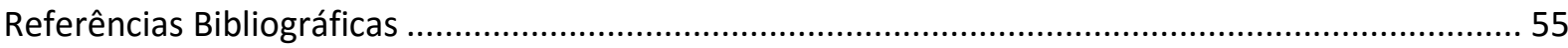

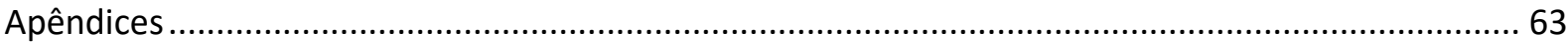


Intradusãa 
O sarcoma de Ewing (SE) é o segundo tumor ósseo maligno mais comum em crianças e adolescentes e pertence a um grupo mais amplo de tumores neuroectodérmicos conhecidos como Família de Tumores de Ewing (FTE). Suas células são caracterizadas por serem indiferenciadas, de origem neuroepitelial, pequenas, redondas e azuis. A incidência anual do SE é de três em 1 milhão de crianças ao ano com menos de 15 anos, sendo 95\% dos casos entre 5 e 25 anos, apesar do diagnóstico ser mais frequente na segunda década de vida. É mais comum em homens, numa proporção de 1,4 para 1 e raramente ocorre em negros e asiáticos (Fletcher et al., 2002; Bernstein et al., 2006; Ferreira et al., 2008; Lissat et al., 2012).

O SE ocorre principalmente nas diáfises de ossos longos das extremidades, como fêmur, tíbia, úmero e fíbula, sendo descrito também em ossos chatos como a pelve, costelas, escápula e crânio (Fletcher et al., 2002; Fukushima et al., 2005; González et al., 2013).

O marcador genético característico é a presença da translocação recíproca envolvendo o os cromossomos 11 e 22, t(11;22)(q24;q12), que está presente em 85\% dos tumores de Ewing (Aurias et al., 1983; Turc-Carel et al, 1988). Outras translocações menos frequentes ocorrem entre o cromossomo 21 e 22 , $\mathrm{t}(21 ; 22)(q 12 ; q 12)$, totalizando cerca de $10 \%$ dos casos, entre o 7 e o 22 , $t(7 ; 22)($ p22;q12), que corresponde a menos de 1\% dos casos (Bernstein et al., 2006; Ferreira, 2008). Entre outras alterações encontradas associadas a um pior prognóstico estão as alterações em 4q21, 5q31, 6p21, 7q12, 10p11.2, 12q14, 14q11, 18p23 e 10q14 (Sandberg \& Bridge, 2000).

A t $(11,22)$ leva a uma fusão do gene EWS no lócus 22q12 com o gene FLI1 no lócus 11q24. Há duas formas de acontecer esta translocação, a partir de uma fusão do éxon 7 do gene EWS com o éxon 6 do gene FLI1 ou de uma fusão do éxon 7 do gene EWS com o éxon 5 do gene FLI1 (Tsugita et al., 2013). Segundo Peter et al. (1997) em $85 \%$ a 90\% dos casos, o terminal amino de EWS é justaposto com o terminal carboxilo de $F L I 1$, resultando na produção e expressão do produto quimérico EWS-FLI1 (Delattre et al., 1992). Esta proteína quimérica possui regiões variáveis, facilitando a interação com inúmeros fatores de transcrição, assim como a ligação e dissociação de complexos de proteínas nucleares que alteram as atividades de transcrição celular (Erkizan et al., 2010).

Esta ligação de EWS-FLI1 a todos estes componentes, leva a indução da transcrição de genes envolvidos na regulação do ciclo celular e reparo do DNA; repressão da expressão de genes envolvidos na adesão celular e migração; e a expressão alterada de genes apoptóticos (Hancock \& Lessnick, 2008; Shaefer, 2008; Kauer, 2009), tendo esta proteína quimérica, portanto, atividade oncogênica (May et al., 1993).

Os sintomas clínicos mais comuns do SE são dor ou edema no local primário do tumor, que pode ser intermitente, variando em intensidade e ocorrendo em $25 \%$ dos pacientes. Segundo o INCA (Instituto Nacional do Câncer) sintomas sistêmicos como febre e perda de peso, anemia, leucocitose e sintomas similares aos de resfriado como mal-estar e fraqueza, são muitas vezes vistos. Fratura 
patológica é uma complicação rara. Radiograficamente, a característica mais comum é o aparecimento de lesão osteolítica mal definida envolvendo a diáfise de um osso tubular longo ou de um osso plano (Fletcher et al., 2002). Pode ser facilmente confundido com osteomielite, devido aos sintomas parecidos, dificultando o diagnóstico. Sintomas semelhantes também aos de neuroblastoma disseminado podem ser apresentados em crianças menores de 5 anos, apesar do SE ser incomum em crianças com esta idade (Bernstein et al., 2006).

Atualmente, o tratamento consiste na aplicação da quimioterapia neoadjuvante, seguida da cirurgia e a quimioterapia adjuvante ou radioterapia, e apesar desta última apresentar um risco de desenvolvimento de osteossarcoma em áreas irradiadas, é indicado para pacientes nos quais o tumor encontra-se em local de difícil remoção cirúrgica (AC Camargo; González et al., 2013).

Existem esquemas específicos multidrogas de acordo com subtipos histológicos do sarcoma. As drogas quimioterápicas mais utilizadas são: doxorubicina, topotecan, ciclofosfamida, vincristina, actinomicina D, ifosfamida e etoposídeo (Macedo \& Petrilli, 1999; Ladenstein et al., 2010; Demicco et al., 2012; Kovar et al., 2012).

Os ensaios clínicos multicêntricos com a aplicação da quimioterapia sistêmica em conjunto com a cirurgia e/ou a radioterapia proporcionou uma melhora na sobrevida dos pacientes, principalmente àqueles com a doença localizada. A sobrevida global atual de 5 anos ocorre em $70 \%$ dos pacientes com a doença localizada, sendo que dois terços têm chance de serem curados. Porém, esta taxa atingiu um patamar na última década. Além disso, a incidência de metástase é muito alta e, apenas 25\% dos pacientes com metástase primária atingem a sobrevida de 5 anos (Laurence et al., 2005; Bernstein et al., 2006; Ladenstein et al., 2010). O prognóstico de crianças e adolescentes com a doença metastásica é ruim e somente $10 \%$ dos que tiveram a doença recorrente sobrevivem a longo prazo (Hunold et al., 2006; Ladenstein et al., 2010).

Devido à rápida disseminação do SE, a presença do tumor metastásico está em 15\% a 30\% dos pacientes no momento do diagnóstico, apresentando metástase principalmente para os pulmões, ossos e medula óssea (West, 2000). As metástases pulmonares correspondem a aproximadamente $50 \%$, ossos e/ou medula óssea $40 \%$ e os casos com envolvimento linfático $10 \%$, podendo raramente ser encontrada metástase no fígado ou sistema nervoso central. Pacientes com metástases pulmonares possuem um prognóstico melhor do que pacientes com envolvimento de ossos ou medula óssea, os quais possuem menos de $20 \%$ de cura com os tratamentos disponíveis atualmente (Macedo \& Petrilli, 1999; Bernstein et al., 2006).

O período de maior risco de recorrência do tumor são os 36 primeiros meses após o início do tratamento e apesar do tratamento multimodal, cerca de $30 \%$ a $40 \%$ dos casos que possuem a doença metastática morrem devido a progressão do tumor. Mahlendorf \& Staege (2013) também citam que o risco de neoplasias secundárias aumenta drasticamente após altas doses de quimioterapia, atingindo cerca de 1 a $2 \%$ dos pacientes. 
Além disso, a agressividade do tumor, a estreita semelhança nos sintomas com doenças não tumorais, o atraso entre o início dos sintomas e o diagnóstico e as baixas sobrevidas, fazem do SE um dos tumores de mais difícil tratamento. A estratégia multimodal atual com terapias direcionadas no qual baseia-se no estudo de alterações moleculares específicas do SE, não está disponível na maioria dos hospitais (Gonzalez et al., 2013).

Nos últimos dez anos, houve uma estagnação na melhora da sobrevida dos pacientes com SE tratados com a quimioterapia clássica, principalmente naqueles que apresentam metástase. Novos agentes antineoplásicos com base em conhecimentos detalhados sobre o SE são necessários para melhorar a sobrevida dos pacientes. A utilização de drogas atuais para efetuar a inibição de vias específicas que estão alteradas neste tumor pode ser uma alternativa para identificação de alvos terapêuticos (Lissat et al., 2012).

A migração e invasão celular dos tecidos vizinhos e vasos sanguíneos, a adesão celular e a proliferação são processos essenciais para que a metástase tumoral aconteça. Na progressão tumoral, as células podem migrar tanto da forma coletiva, como da forma individual, sendo os principais tipos de movimento desta última, o movimento ameboide e mesenquimal, dependendo do microambiente em que as células estão presentes (Ginsberg et al., 2001). O tipo ameboide é o mais simples, em que a célula adquire formato arredondado, é mais rápida e menos adesiva, passando por entre as fibras da matriz extracelular (Figura 1). Já na migração mesenquimal, a célula é fusiforme alongada e muito adesiva, passando pelas fibras da matriz extracelular com o auxílio de proteases (Friedl \& Wolf, 2003; Schmidt \& Friedl, 2010).

Em ambos os tipos de movimento, a célula perde a adesão com suas células vizinhas e passa a migrar sozinha, invadindo estroma e tecidos próximos, dependendo assim da remodelação do citoesqueleto de actina tanto na migração mesenquimal, para adesão à matriz extracelular, como na migração ameboide, para gerar força contrátil (Friedl \& Wolf, 2003; Montenegro, 2011).

Os dois tipos de migração não ocorrem ao mesmo tempo, ou seja, são mutuamente excludentes e influenciados pelo microambiente em que se encontram. Quando a matriz extracelular é mais macia, ocorre preferencialmente uma migração mesenquimal, que é regulada pela via Rac. Por outro lado, quando a matriz é mais rígida, uma migração do tipo ameboide é favorecida, que é controlada pela via Rho-ROCK (Sahai \& Marshall, 2003; Amin et al., 2013).

As GTPases da família Rho são reguladoras da mobilidade e adesão celular. Elas estão envolvidas na organização dos filamentos de actina e são controladoras de processos biológicos como proliferação, migração, adesão, diferenciação, apoptose, citocinese, expressão gênica, tráfego intracelular e progressão do ciclo celular (Nakagawa et al., 1996; Pinheiro, 2010; Tseliouet al, 2016). As proteínas Rho mais bem caracterizadas são: RhoA, RhoB, Rac1 e Cdc42 (Hall, 1998; Heasman and Ridley, 2008). 
A

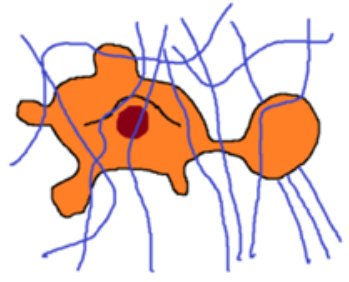

Migração ameboide
B

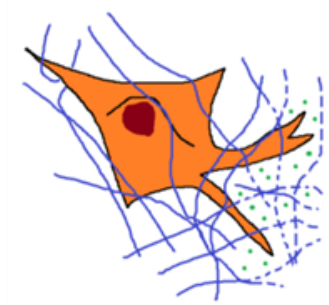

Migração mesenquimal

Figura 1: A) Migração amebóide, guiada pela reestruturação e contração de filamentos de actomiosina. B) Migração menquimal, envolvendo a degradação da matriz extracelular [adaptado de Narumiya et al., (2009) por M.S. Brassesco].

Dentre as proteínas efetoras de Rho estão as proteínas quinases associadas a Rho, ou proteínas ROCK, que são codificadas pelo gene Rho-associated coiled-coil kinase (ROCK) e são conhecidas duas formas homólogas, ROCK1 e ROCK2. As proteínas ROCK são quinases de serina-treonina de 160 kDa, que apresentam $65 \%$ de homologia nas suas sequências de aminoácidos e até $92 \%$ no domínio quinase, o que pode explicar a similaridades de seus alvos (Figura 2). São ubiquamente expressas, porém, ROCK1 é preferencialmente expressa no fígado, baço, rins, pulmões e testículos e ROCK2 é predominante em outros tecidos como cérebro e músculos esqueléticos (Nakagawa et al., 1996; Shi et al., 2013).

A

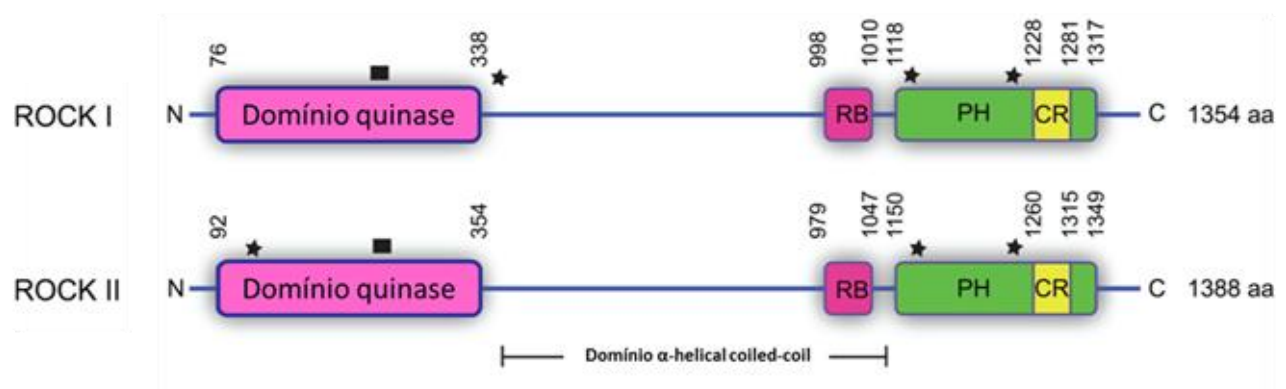

B

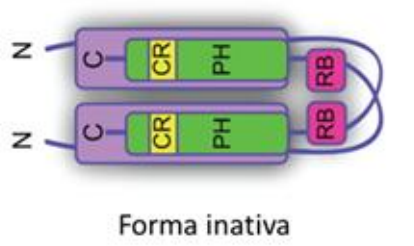

C

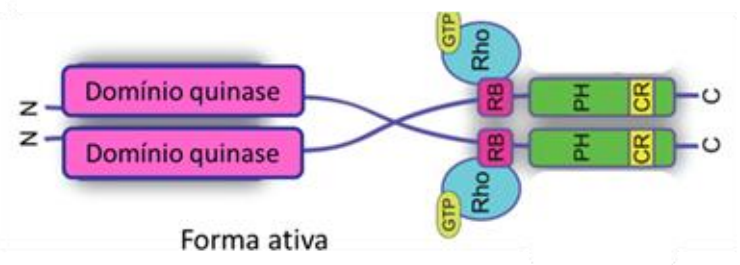

Figura 2: A) Domínios estruturais das proteínas ROCK1 e ROCK2; Homodímeros de proteínas ROCK demonstrando sua forma inativa (B) e sua forma ativa (C) após ligação de Rho-GTP [adaptado de MorganFisher et al., (2013) por M. S. Brassesco]. 
As proteínas ROCK possuem um domínio $\mathrm{N}$-terminal quinase ou o domínio catalítico (CD), um domínio coiled-coil (filamento helicoidal) contendo um domínio de ligação a Rho (RBD) e um domínio C-terminal rico em cisteína (CRD) de homologia a plecstrina (PH) (Matsui et al., 1996). O domínio Cterminal, incluindo o domínio PH e juntamente com o RBD, é uma região auto-inibidora que inibe sua atividade quinase sob condições basais via associação intramolecular com o domínio quinase (Figura 2). Por outro lado, a ligação de proteínas homólogas a ROCK em seu domínio quinase N-terminal, aumenta a auto-fosforilação, sugerindo que a dimerização pode promover a atividade de ROCK (Schofield \& Bernard, 2013). Todas as três proteínas Rho podem se ligar ao domínio RBD de ROCK, e estando carregadas com moléculas de GTP, aumentam a atividade catalítica através da indução de alterações conformacionais que diminuem a auto-inibição pelo domínio C-terminal (Dvorsky et al., 2004).

ROCK exibe a sua atividade biológica através de fosforilação de uma série de alvos, sendo os principais: a cadeia leve da miosina (MLC), a fosfatase 1 (MYPT1), a miosina de cadeia leve 2 (MLC2) e as LIM quinases, que regulam a organização do citoesqueleto de actina, a formação de fibras de estresse e a contração celular (Kimura et al., 1996; Maekawa et al., 1999; Ohashi et al., 2000). As proteínas ROCK podem aumentar a fosforilação da MLC diretamente pela sua fosforilação ou indiretamente pela inativação de MYPT1, resultando na contratilidade das fibras de actina (Kimura et al., 1996). As proteínas ROCK estabilizam os filamentos de actina através da ativação das LIM quinases, resultando na fosforilação de cofilina que irá inibir sua atividade de despolimerização da actina. Ambos os caminhos, ROCK/MYPT1/MLC e ROCK/LIMquinase/cofilina estão fortemente envolvidos na montagem de fibras de estresse e adesão celular (Shi et al., 2013).

As proteínas ROCK1 e ROCK2 também estão envolvidas na regulação da proliferação celular e da citocinese e são ativadas durante o ciclo celular, tanto em G1 quanto na mitose (Izawa et al., 1998; Pawlak \& Helfman, 2002). A hiperexpressão constitutiva de ROCK1 e ROCK2 aumenta a proliferação celular e sua ativação induz um aumento na expressão de $\beta$-catenina, assim como de seu alvo de transcrição c-myc, acarretando também, um aumento da proliferação (Kosako et al., 2000). Por outro lado, as proteínas ROCK são ativadas durante a citocinese, contribuindo para a formação dos sulcos de clivagem ricos em actina e a desmontagem dos filamentos intermediários abaixo do sulco de clivagem (Matsumura, 2005; Izawa \& Inagaki, 2006). A inibição de ROCK causa então, um atraso na segregação das células filhas, sendo sua regulação precisa muito importante na citocinese (Kosako et al., 2000).

Portanto, ROCK1 e ROCK2 induzem inúmeras respostas celulares que envolvem a regulação de muitas proteínas associadas ao citoesqueleto (Figura 3). É cada vez mais evidente que tais respostas sinalizadas pelas proteínas ROCK agravam muitos fenótipos associados ao câncer e outras doenças cardiovasculares, neurológicas, de insuficiência renal, asma, glaucoma, osteoporose e de resistência 
à insulina, podendo ser uma molécula promissora para o tratamento destas inúmeras patologias (Olson, 2008; Pan et al., 2013; Schofield \& Bernard, 2013).

Diversos trabalhos têm mostrado a relação das proteínas ROCK com muitas destas patologias, e a inibição das mesmas através de drogas ou RNA de interferência (siRNA) tem sido visto como uma nova e importante estratégia terapêutica para estas doenças. Samuel et al (2011), mostraram que a expressão de ROCK induz a formação de tumores em câncer de pele; Schofield \& Bernard (2013), por outro lado, citam a inibição por fosforilação de ROCK importante em melanoma.

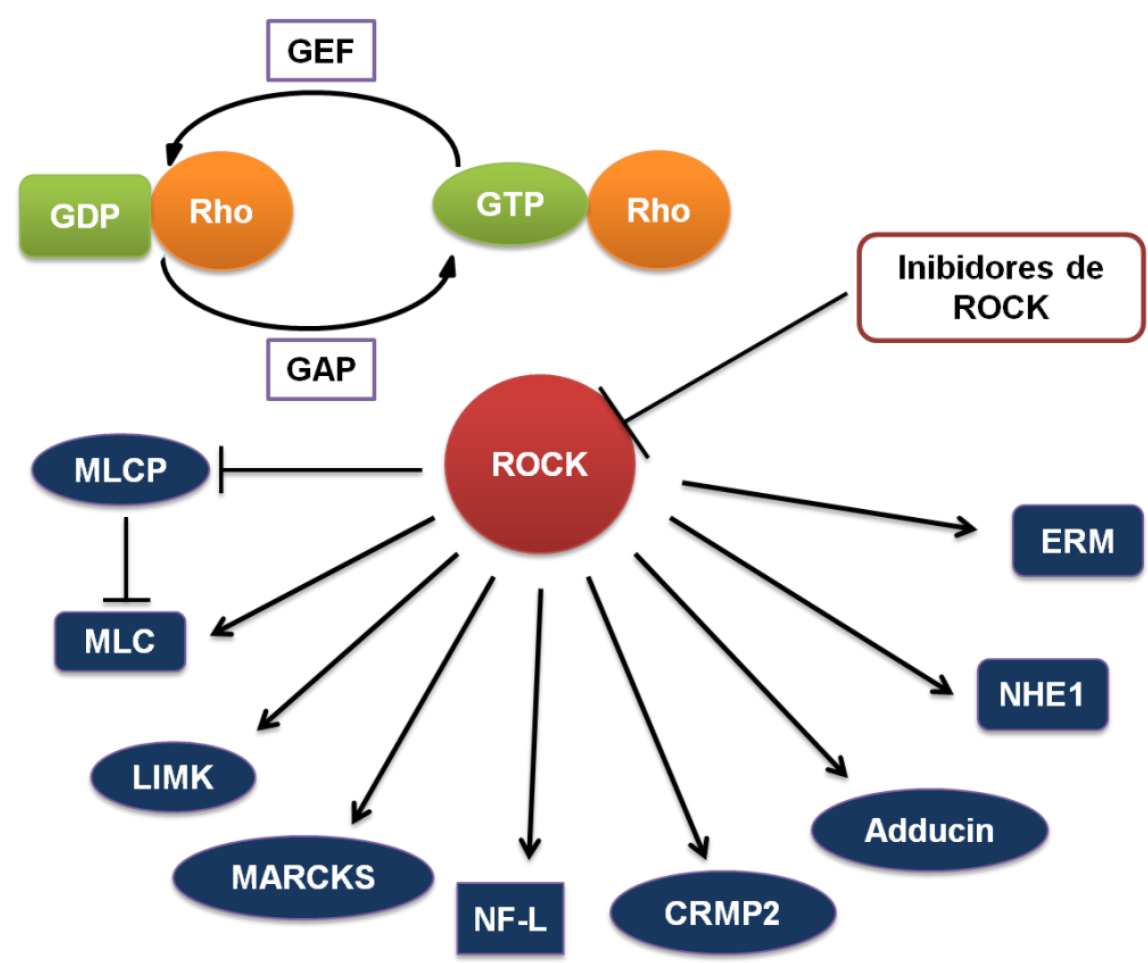

Figura 3: Sinalização da via das proteínas ROCK (Adaptado de Feng et al., 2015).

Segundo dados de Mertsch \& Thanos (2014), as ROCKs também são candidatos na terapia do glioblastoma. Os autores demonstraram que o bloqueio de ambas as isoformas de ROCK com inibidores farmacológicos regulam o processo de migração. Constataram ainda, que a ativação equilibrada de ROCK é responsável pela proliferação de células de glioblastoma e pela migração específica conforme o substrato.

Liu et al. (2009) observaram que inibindo ROCK com Y27632 ou pequenos siRNA, a migração e a proliferação celular é impedida em in vitro e a metástase diminuída in vivo em osso humano.

Visto que a via de sinalização de ROCK é importante em toda esta vasta gama de doenças, além de estar envolvida em vários tipos de câncer como mama, pulmão, cólon, fígado, cabeça, pescoço, testicular, de bexiga; que a expressão aberrante de ROCK induz a metástase de vários tipos tumorais; e a inibição da via ROCK poderia diminuir significativamente o crescimento de tumores em modelos in vitro e in vivo (Pan et al., 2013); propomos neste trabalho verificar a expressão dos genes 
ROCK1 e ROCK2 em amostras de pacientes com SE e linhagens celulares de SE e os efeitos in vitro da inibição das mesmas a partir do uso das drogas GSK429286, SR3677 e Hidroxifasudil sob diferentes aspectos de invasão e proliferação celular em linhagens celulares de SE. 
Objelives 


\subsection{Objetivo Geral}

O principal objetivo do presente trabalho foi avaliar a expressão de ROCK1 e ROCK2 (mRNA) em amostras de pacientes acometidos por SE e verificar in vitro os efeitos da inibição das proteínas a partir do uso de drogas sintéticas em linhagens celulares de SE.

\subsection{Objetivos Específicos}

- Avaliar os níveis de expressão dos genes ROCK1 e ROCK2 e através de PCR em tempo real em amostras tumorais de pacientes diagnosticados com SE.

- Analisar a associação entre os níveis de expressão de ROCK1 e de ROCK2 e características ao diagnóstico e evolução clínica dos pacientes;

- Verificar os efeitos da inibição das proteínas ROCK em linhagens celulares de SE por meio das drogas sintéticas GSK429286 (inibidora de ROCK1), SR3677 (inibidora de ROCK2) e Hidroxifasudil (pan-inibidor) utilizando os ensaios de proliferação celular, capacidade clonogênica, migração por wound healing assay, invasão em matrigel e ciclo celular. 
Material e Metados 
Os experimentos foram realizados no laboratório de Pediatria do Hospital das Clinicas da Faculdade de Medicina de Ribeirão Preto da Universidade de São Paulo (HC/FMRP-USP).

\subsection{Casuística}

Foram utilizadas 18 amostras microdissecadas de pacientes portadores de SE, além de oito amostras de osso não-neoplásico disponíveis no banco de tumores (9375/2003) do Laboratório de Pediatria (HC/FMRP-USP) e 9 amostras de linhagens primárias de osteoblasto (gentilmente cedidas pelo Prof. Dr. Adalberto Luiz Rosado do Departamento de Cirurgia e Traumatologia Buco-MaxiloFacial (TBMF) e Periodontia da Faculdade de Odontologia de Ribeirão Preto - USP), que foram escolhidas para serem comparadas com as amostras tumorais de pacientes. Foram obtidos os dados clínicos dos pacientes e avaliada a associação da expressão gênica de ROCK1 e ROCK2 das amostras de SE com características biológicas e com o prognóstico.

\subsection{Linhagens Celulares e Condições de Cultura}

Para o estudo, as linhagens celulares utilizadas foram RD-ES e SK-ES-1, adquiridas através do Banco de Células do Rio de Janeiro da UFRJ. Estas linhagens celulares foram cultivadas em meio apropriado (RPMI ou McCoy, respectivamente) suplementado com $100 \mathrm{mg} / \mathrm{mL}$ de estreptomicina, $60 \mathrm{mg} / \mathrm{L}$ de penicilina, e $10 \%$ ou $15 \%$ de soro bovino fetal (SBF) (pH 7.2-7.4) em atmosfera úmida contendo $5 \% \mathrm{CO}_{2}$ a $37^{\circ} \mathrm{C}$.

\subsection{Tratamento de cultivos com drogas}

Os inibidores de quinases ROCK GSK429286 (inibidor seletivo de ROCK1), SR3677 (inibidor seletivo de ROCK2) e Hidroxifasudil (pan-inibidor) foram adquiridos da Sigma-Aldrich (St. Louis, MO, USA). As soluções estoque foram diluídas em DMSO $(2,5 \mathrm{mg} / \mathrm{mL})$, filtradas em filtro millipore $(0,5 \mu \mathrm{m})$ e estocadas a $-20^{\circ} \mathrm{C}$ em alíquotas menos concentradas. As drogas foram adicionadas em meio de cultura imediatamente antes de serem aplicadas nas células. Como veículo da droga, foi utilizado o DMSO e todas as doses utilizadas de GSK429286 e SR3677 estavam com a concentração de DMSO de $0,5 \%$ e a droga Hidroxifasudil com a concentração de $1 \%$ de DMSO, que não causam danos nas células.

\subsection{Amostras de pacientes}

As amostras de SE $(n=18)$ foram coletadas pelo serviço de Ortopedia Oncológica HC-FMRP do Departamento de Biomecânica, Medicina e Reabilitação do Aparelho Locomotor da FMRP-USP. Imediatamente após da cirurgia, as mesmas foram congeladas a $-80^{\circ} \mathrm{C}$ e estocadas no Banco de Tumores do Laboratório de Oncologia Pediátrica do Hospital das Clínicas (aprovado pelo Comitê de Ética em Pesquisa Processo 9373/2003) da Faculdade de Medicina de Ribeirão Preto da Universidade 
de São Paulo (FMRP-USP). Todas as amostras foram obtidas após assinatura do termo de consentimento pelos pacientes ou seus responsáveis. O presente trabalho foi aprovado pelo comitê de ética institucional (processo no 43619215.9.0000.5407).

\subsection{Extração de RNA, qRT-PCR e PCR convencional}

O mRNA foi extraído por meio do Reagente de Trizol (Invitrogen Inc, Carsdab, CA) de acordo com as instruções do fabricante. O RNA foi quantificado e armazenado em freezer $-80^{\circ} \mathrm{C}$ até a sua utilização. O cDNA dos mRNAs-alvo Foi sintetizado por meio do kit High capacity (Applied Biosystems, Foster City, CA, EUA).

A qRT-PCR para verificar a expressão dos genes ROCK1 e ROCK2 foi realizada utilizando o aparelho ABI Prism 7500 Sequence Detector (Applied Biosystems, Foster City, CA, EUA). Os primers e as sondas $\operatorname{TaqMan}^{\circledR}$ foram adquiridas pelo sistema by-demand da Applied Biosystems. A concentração final dos primers e das sondas Taqman ${ }^{\circledR}$ foram $900 \mathrm{nM}$ e $300 \mathrm{nM}$, respectivamente. 0 volume final para cada PCR foi de $10 \mu \mathrm{L}$, incluindo $4,5 \mu \mathrm{L}$ de amostra investigada diluída (1/10), $5 \mu \mathrm{L}$ Universal PCR Master Mix (Applied Biosystems, Foster City, CA, EUA) e 0,5 $\mu \mathrm{L}$ de sonda. Foram utilizados como genes de referência GUSB (glucuronidase beta) e ACTB (beta-actina). A quantificação relativa da expressão gênica foi determinada utilizando o método $2^{-\Delta \triangle C T}$ (Livak \& Schmittgen, 2001).

As reações de PCR convencional foram realizadas utilizando-se $1 \mu \mathrm{L}$ de CDNA, com $2,5 \mu \mathrm{L}$ de tampão Buffer (5X GoTaq Flexi, Promega, Madison, WI, USA), 0,75 $\mu \mathrm{L}$ de MgCL2, 0,5 $\mu \mathrm{L}$ de dNTP, $0,5 \mu \mathrm{L}$ de cada primer, 0,2 $\mu \mathrm{L}$ de Taq polimerase e 19,05 $\mu \mathrm{L}$ água de seringa, apresentando um volume final de $25 \mu \mathrm{L}$. Os primers utilizados foram o EWS (5' TCC TAC AGC CAA GCT CCA AGT C 3') e o FLI (5' ACT CCC CGT TGG TCC CCT CC 3'). As reações de PCR foram realizadas no termociclador (Veriti 96 Well Thermal Cycler, Applied Biosystems, EUA). As reações foram mantidas a $-4^{\circ} \mathrm{C}$ até a sua análise por eletroforese em gel de agarose (2\%). Os produtos de PCR foram aplicados no gel com tampão TBS 1X e corados com brometo de etídio. Posteriormente, foram visualizados através da exposição a luz UV e fotografados no sistema Bio-Imaging Systems da Uniscence e o programa Gel Gapture.

\subsection{Ensaio de Proliferação Celular}

Para esse ensaio, as células foram semeadas em densidades iniciais de $2 \times 10^{3}$ células por poço, sendo posteriormente testadas as concentrações variando de $3,5 \times 10^{3}$ a $5 \times 10^{3}$ em placas de 96 poços e mantidas em condições de cultura por $24 \mathrm{~h}$. Após este período, as células foram tratadas e incubadas com os diferentes tratamentos por $24,48,72$ e 96 h. A cada intervalo de tratamento, a remoção do meio de cultura dos poços foi realizada e adicionados $100 \mu \mathrm{L}$ de meio de cultura com 10 $\mu \mathrm{L}$ de XTT (Sigma, ST. Louis, MO, USA) em cada poço e as placas incubadas por mais $4 \mathrm{~h}$ em atmosfera úmida contendo $5 \% \mathrm{CO}_{2}$ a $37^{\circ} \mathrm{C}$. A leitura da absorbância de $655 \mathrm{~nm}$ foi realizada utilizando 
o aparelho iMark Microplate Absorbance reader (BioRad Laboratories, Inc., CA, EUA). Os resultados estão expressos como média e desvio padrão.

\subsection{Ensaio de Capacidade Clonogênica}

Para este ensaio, 1000 células foram semeadas por poço em placas de seis poços. As células foram tratadas e incubadas com os diferentes tratamentos por $48 \mathrm{~h}$ e então voltaram para estufa para incubação por 10 dias a 15 dias, tempo suficiente para a formação de colônias. Para visualização das colônias, o meio de cultura foi descartado e as células foram fixadas com metanol absoluto e coradas com Giemsa (3\%). A contagem foi realizada com auxílio de estereomicroscópio (40x) e foram consideradas apenas colônias com número de células maior ou igual a 50. Os resultados estão expressos como média e desvio padrão.

\subsection{Ensaio de Invasão celular em Matrigel}

As células foram tripsinizadas, contadas e ressuspensas em meio de cultura sem SBF tratado com as diferentes concentrações das drogas inibidoras de ROCK. Posteriormente, $5 \times 10^{5}$ células foram colocadas no topo da matriz de matrigel do kit BD BiocoatTM MatrigelTM Matrix-24 well plate (Becton, Dickinson and Company, NJ, EUA). Na parte inferior do inserto foi adicionado meio de cultura com $10 \%$ de SBF. Após a incubação a $37^{\circ} \mathrm{C}$ por $24 \mathrm{~h}$, as células que não invadiram foram removidas da parte superior do inserto com o uso de um swab (tipo de cotonete). As células que invadiram foram fixadas com metanol $100 \%$ por 15 minutos e coradas com uma solução de Giemsa $3 \%$. As membranas do inserto foram removidas posteriormente, montadas em lâminas de vidro com Entellan (Merk ${ }^{\circledR}$ ) e fotografadas ao microscópio de luz clara (magnificação de 100x) sendo contadas com o auxílio do software Image-J, versão 1.48 (Abramoff et al., 2004). Os resultados estão expressos como média e desvio padrão.

\subsection{Ensaio de migração por wound healing assay}

Os ensaios de migração in vitro foram realizados de acordo com Liang et al. (2007) com pequenas modificações. Resumidamente, as células foram mantidas em meio de cultivo até confluência em placa de 12 poços e então foram realizadas "feridas" com o auxílio de uma ponteira de $200 \mu \mathrm{L}$. No tempo zero, o sítio de ferida foi fotografado. As células foram então tratadas com as diferentes concentrações das drogas por $24 \mathrm{~h}$ em meio de cultivo suplementado com 1\% de SBF. Após esse período, as células foram fixadas em metanol, coradas com Giemsa 3\% e fotografadas. 0 software Motic Images Plus v2.0 (Motic China Group Co., Ltd) foi utilizado para calcular a área livre de células. A taxa de migração foi calculada então como a distância em nanômetros migrada ao longo do tempo. Os resultados estão expressos como média e desvio padrão. 


\subsection{Avaliação do Ciclo Celular}

Para a avaliação das fases do ciclo celular, $1,5 \times 10^{5}$ células foram semeadas em placas de 6 poços e tratadas com as drogas por 24 h. Após o tratamento, as células foram fixadas em etanol 100\%, coradas com iodeto de propídeo $(1 \mathrm{mg} / \mathrm{mL})$ e analisadas. Foram analisadas 5000 células utilizando o programa Guava CytoSoft 4.2.1 (Guava Technologies, Hayward, CA). A progressão do ciclo celular foi avaliada através de verificação da quantidade de DNA presente na célula. $O$ iodeto de propídeo cora especificamente o DNA e através da citometria de fluxo a quantidade do mesmo é mensurada e o ciclo celular em que a célula se encontra (G1, S ou G2/M) é determinada.

\subsection{Forma de análise dos resultados}

Para análise da dinâmica de expressão gênica foi utilizado o teste não paramétrico de Mann Whitney, com o auxílio dos softwares Graph Prism 5.0 (GraphPad Software, San Diego, CA, USA) e SPSS 21.0 (SPSS Inc. Chicago, USA) para análise da relação entre a expressão gênica das amostras tumorais e os dados clínicos dos pacientes. Para analisar as diferenças entre os tratamentos foi realizada One Way ANOVA seguido pelo teste de Bonferroni. Foi considerado nível de significância $\alpha \leq 0,05$. 
OPesultados 


\subsection{Dados clínicos dos pacientes}

As características clínicas dos pacientes avaliadas foram sexo, idade, metástase, localização, recidiva, óbito, grau de necrose, tamanho do tumor, presença do gene de fusão EWS-FLI1, verificando se há uma associação das mesmas com as expressões dos genes ROCK1 e ROCK2 nas amostras de pacientes com SE. A Tabela 1 resume estes dados.

Foram analisadas amostras de sete pacientes do gênero feminino (39\%) e onze do gênero masculino (61\%), com média de idade de 14 anos (variação de idade de 4 a 28 anos). Para análise, as amostras foram divididas em dois grupos, amostras de pacientes com uma idade menor ou igual a 14 anos (10 pacientes - 56\%) e amostras de pacientes com mais de 14 anos (8 pacientes $-44 \%$ ). A localização dividiu as amostras dos pacientes em dois grupos, os que possuíam tumor com localização axial (4 pacientes - 22\%) e os que possuíam tumor com localização apendicular (14 pacientes $-77 \%)$.

Foi avaliada a presença de metástase ao diagnóstico, estando presente em apenas cinco pacientes $(28 \%)$, sendo quatro pulmonares e uma em linfonodo inguinal. Quanto aos dados relacionados aos eventos de recidiva e/ou óbito, nove pacientes sofreram recidiva (50\%), sete pacientes (38\%) estão vivos sem a doença, outros cinco pacientes (28\%) estão vivos, porém com a doença e cinco pacientes (28\%) foram a óbito.

O grau de necrose segundo o critério de Huvos também foi analisado, considerando os graus de 1 a 4 . Os graus 1 e 2 correspondem a pouca necrose pós-quimioterapia e consequentemente uma pior resposta ao tratamento, e os graus 3 e 4 correspondem a muita necrose e consequentemente uma boa resposta ao mesmo. Dois pacientes (11\%) apresentaram grau 1, um paciente (5\%) apresentou grau 2, quatro pacientes (22\%) apresentaram grau 3, seis pacientes (33\%) apresentaram grau 4 e somente um (5\%) não apresentou necrose. Dos quatro restantes (22\%), tais informações não estavam disponíveis. O tamanho também foi calculado, sendo que tumores com até $200 \mathrm{~cm}^{3}$ foram considerados pequenos e os maiores que $200 \mathrm{~cm}^{3}$ foram considerados grandes. Sete pacientes (39\%) possuíam tumor grande e a outros oito (44\%), tumor pequeno.

Para detectar a presença do gene de fusão EWS-FLI1 nos pacientes, foi realizado PCR convencional e eletroforese em gel de agarose. Dos 18 pacientes estudados, 15 apresentaram o gene de fusão, representando $83 \%$ de positividade, como pode ser observado na Figura 4. 
Tabela I. Dados clínicos referentes à idade, sexo, tamanho do tumor, huvos, metástase, localização e status dos pacientes incluídos no estudo.

\begin{tabular}{|c|c|c|c|c|c|c|c|c|c|c|}
\hline Paciente & Idade & Sexo & Cor & EWS-FLI1 & Tamanho & Huvos & Metástase & Localização & Status & Recidive \\
\hline 1 & 17 & $\mathrm{~F}$ & Parda & Negativo & $1396,5 \mathrm{~cm}^{3}$ & $\begin{array}{c}\text { Não } \\
\text { informado }\end{array}$ & Não & Escápula Direita & Vivo sem a doença & Não \\
\hline 2 & 4 & M & Branca & Positivo & $320 \mathrm{~cm}^{3}$ & $\begin{array}{c}\text { Ausência de } \\
\text { necrose }\end{array}$ & Pulmonar & $\begin{array}{c}\text { Toraco-abdominal } \\
\text { invertebral }\end{array}$ & Óbito & Sim \\
\hline 3 & 18 & $\mathrm{~F}$ & Branca & Positivo & $95,61 \mathrm{~cm}^{3}$ & Grau 4 & Não & Úmero direito & Óbito & Sim \\
\hline 4 & 15 & $\mathrm{~F}$ & Branca & Positivo & $26 \mathrm{~cm}^{2}$ & Grau 4 & Não & Fêmur direito & Vivo sem a doença & Não \\
\hline 5 & 14 & M & Branca & Positivo & $513,24 \mathrm{~cm}^{3}$ & $\begin{array}{c}\text { Não } \\
\text { informado }\end{array}$ & Pulmonar & Fíbula & Óbito & Sim \\
\hline 6 & 20 & M & Branca & Positivo & $4875 \mathrm{~cm}^{3}$ & Grau 2 & $\begin{array}{c}\text { Linfonodos } \\
\text { inguinais }\end{array}$ & Fêmur esquerdo & Óbito & Não \\
\hline 7 & 12 & $\mathrm{~F}$ & Branca & Positivo & $81,01 \mathrm{~cm}^{3}$ & Grau 3 & Não & Fíbula direita & Vivo sem a doença & Não \\
\hline 8 & 13 & $\mathrm{~F}$ & Branca & Positivo & $67,5 \mathrm{~cm}^{3}$ & $\begin{array}{c}\text { Não } \\
\text { informado }\end{array}$ & Não & Fíbula direita & Vivo & Não \\
\hline 9 & 17 & $\mathrm{~F}$ & Branca & Positivo & & Grau 4 & Não & Coxa direita & Vivo sem a doença & Não \\
\hline 10 & 16 & M & Branca & Positivo & $2148,6 \mathrm{~cm}^{3}$ & Grau 3 & Pulmonar & Fêmur e tíbia direita & Vivo com a doença & Sim \\
\hline 11 & 16 & $\mathrm{~F}$ & Branca & Positivo & & Grau 4 & Não & Púbis/Pelve & Vivo sem a doença & Não \\
\hline 12 & 6 & M & Branca & Negativo & & Grau 4 & Não & Fêmur esquerdo & Vivo com a doença & Sim \\
\hline 13 & 12 & M & Branca & Positivo & $1870 \mathrm{~cm}^{3}$ & $\begin{array}{c}\text { Não } \\
\text { informado }\end{array}$ & Não & Osso ilíaco esquerdo & Óbito & Sim \\
\hline 14 & 10 & $M$ & Branca & Positivo & $221,67 \mathrm{~cm}^{3}$ & Grau 4 & Não & Úmero direito & Vivo sem a doença & Não \\
\hline 15 & 9 & M & Branca & Positivo & $154,22 \mathrm{~cm}^{3}$ & Grau 3 & Não & Fíbula direita & Vivo com a doença & Sim \\
\hline 16 & 28 & M & Branca & Positivo & $2415 \mathrm{~cm}^{3}$ & Grau 1 & Pulmonar & Coxa & Vivo com a doença & Sim \\
\hline 17 & 9 & M & Branca & Negativo & $154,22 \mathrm{~cm}^{3}$ & Grau 3 & Não & Fíbula direita & Vivo com a doença & Sim \\
\hline 18 & 11 & M & Branca & Positivo & $135,46 \mathrm{~cm}^{3}$ & Grau 1 & Não & Tórax & Vivo sem a doença & Não \\
\hline
\end{tabular}

M 1 $\begin{array}{llllllllll}2 & 3 & 4 & 5 & 6 & 7 & 8 & 9 & 10 & 11\end{array}$ M 12 $\begin{array}{lllllll}13 & 14 & 15 & 16 & 17 & 18 & \mathrm{CP}\end{array}$
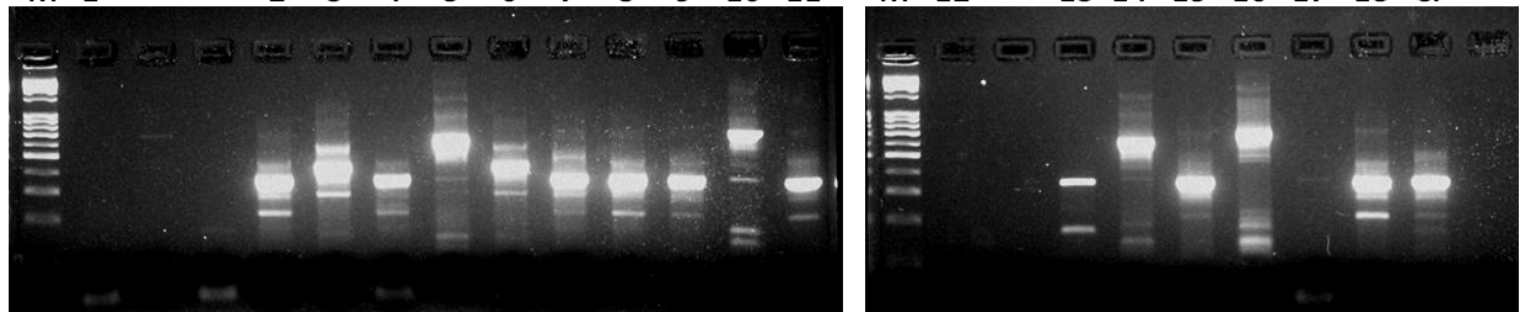

Figura 4: Gel de agarose 2\% mostrando os pacientes positivos para o gene de fusão EWS-FLI1. Os pacientes não identificados não foram diagnosticados com SE. A diferença nos tamanhos das bandas corresponde a diferentes pontos de quebra entre os pacientes. $\mathrm{CT}=$ controle positivo; $\mathrm{M}=$ marcador de peso molecular (ladder de $1 \mathrm{~kb}$ Invitrogen).

\subsection{Expressão dos genes $R O C K 1$ e $R O C K 2$ e relação com dados clínicos}

Primeiramente, foi realizada a análise para a escolha dos melhores genes de referência para serem utilizados na PCR em tempo real. Esta análise avaliou a expressão dos genes de referência GAPDH, HPRT, GUSB e ACTB nas amostras de pacientes com SE, osteossarcoma e nas linhagens MRC5 (fibroblasto normal), SK-ES-1 (sarcoma de Ewing) e HOS (osteossarcoma). Foi constatado que 
os genes mais estáveis, portanto mais adequados para serem utilizados como referência, foram os genes GUSB e ACTB.

A linhagem celular MRC5 foi utilizada como calibrador em todos os experimentos de análise de expressão das amostras tumorais de SE. Para comparação com as amostras e linhagens de SE, foram utilizados dois grupos controles nas análises de expressão gênica de ROCK1 e ROCK2, sendo eles 8 amostras de osso não neoplásico e 9 amostras primárias de osteoblasto (provenientes de amostras de mandíbulas não neoplásicas). Todas as amostras foram avaliadas em duplicata por PCR em tempo real.

Após análise, foi observado que as amostras tumorais de SE apresentaram níveis de expressão dos genes ROCK1 e ROCK2 estatisticamente menores do que os níveis de expressão dos dois grupos de amostras controle. As linhagens celulares RD-ES e SK-ES-1 também apresentaram menores níveis de expressão dos genes ROCK1 e ROCK2 (Figuras 5 e 6). Os gráficos mostram as expressões em forma de média. Estes dados estão detalhados no apêndice $A$.

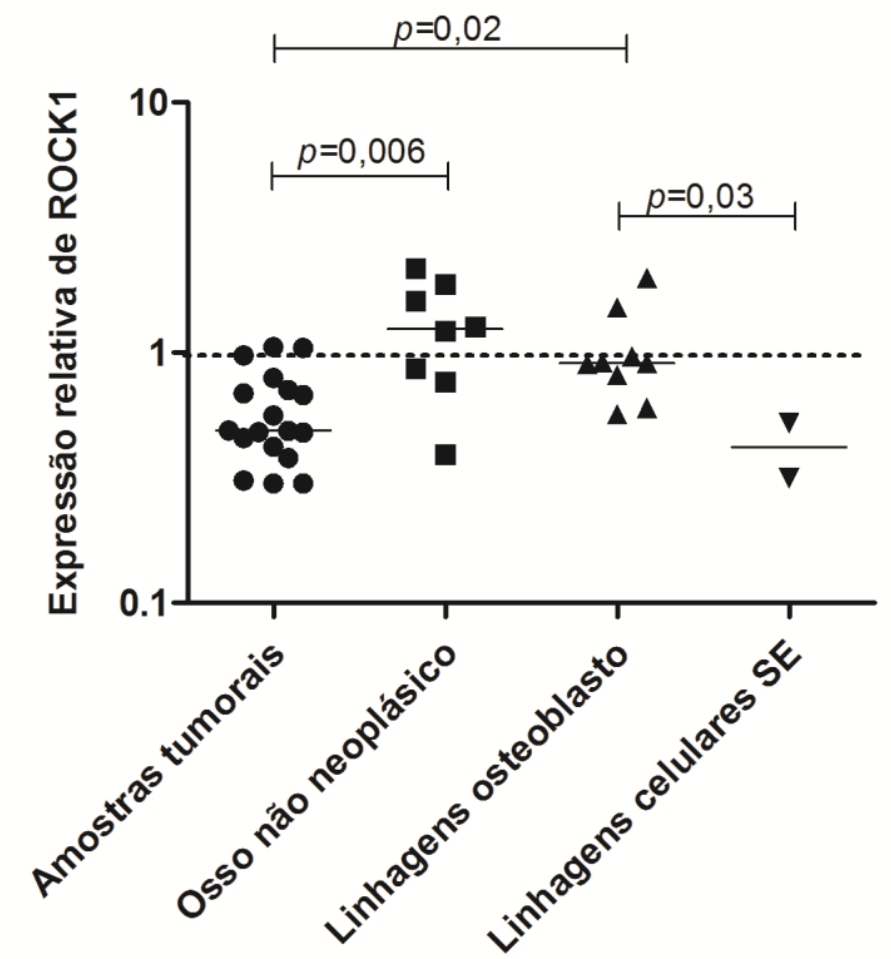

Figura 5: Expressão relativa do gene ROCK1 em amostras de pacientes com SE, em amostras de osso não neoplásico, nas linhagens primárias de osteoblasto e nas linhagens celulares SK-ES-1 e RD-ES. As chaves representam diferença significativa entre os grupos analisados $(p \leq 0,05)$. 


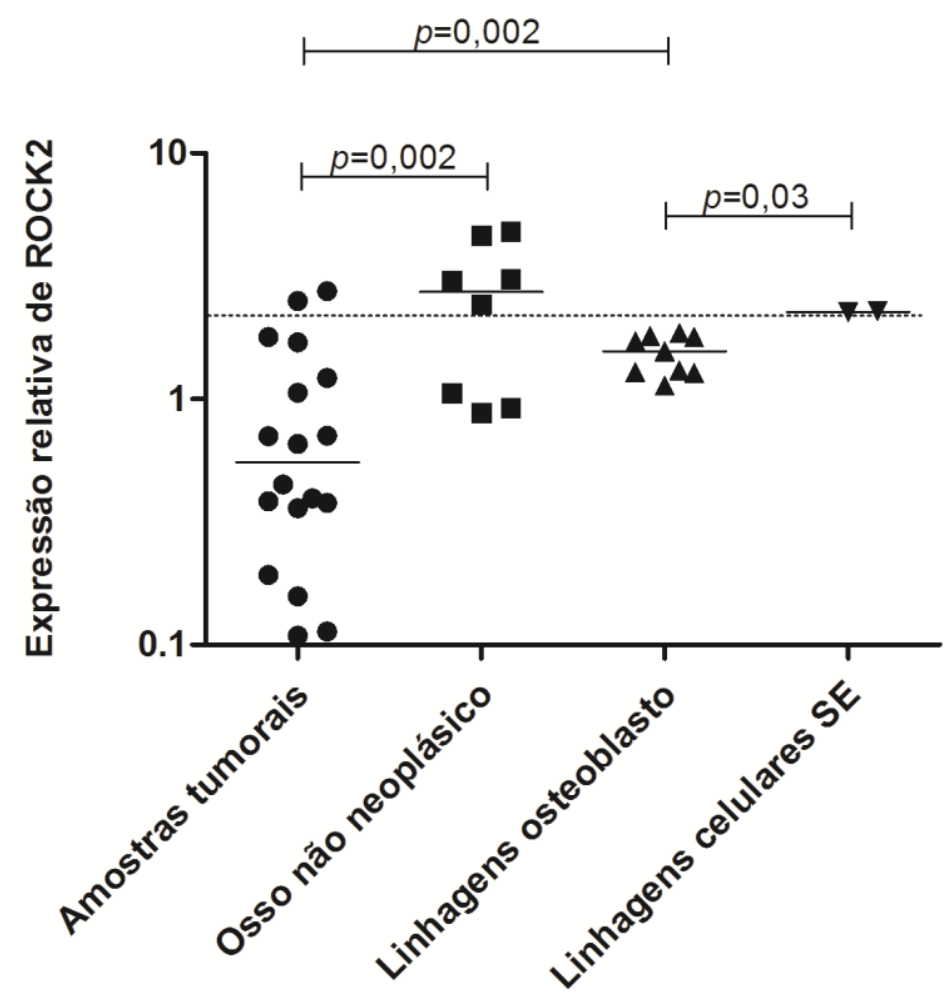

Figura 6: Expressão relativa do gene ROCK2 em amostras de pacientes com SE, em amostras de osso normal, nas linhagens de osteoblasto e nas linhagens celulares SK-ES-1 e RD-ES. As chaves representam diferença significativa entre os grupos analisados $(p \leq 0,05)$.

As amostras tumorais revelaram o valor de $p$ de 0,006 para ROCK1 e 0,002 para ROCK2 quando comparadas aos ossos não neoplásicos. Quando comparadas aos osteoblastos, apresentaram o valor de $p$ de 0,02 para ROCK1 e 0,002 para ROCK2. Já as linhagens celulares, apresentaram o valor de $p$ de 0,06 para ROCK1 e 0,6 para ROCK2 quando comparadas aos ossos não neoplásicos. Quando comparadas aos osteoblastos, apresentaram o valor de $p$ de 0,03 para ROCK1 e o mesmo valor para ROCK2.

Pode-se observar também que todas as amostras em questão (tumorais, osso normal e linhagens celulares) estão com a expressão um pouco mais elevada de ROCK2 do que de ROCK1 (Figuras 5, 6 e 7). Além disso, especialmente nas amostras tumorais, ROCK2 está com a expressão mais elevada, porém também com maior variação das expressões do que ROCK1 (Figura 7).

Ao relacionar a expressão dos genes ROCK1 e ROCK2 e as características clínicas e biológicas dos pacientes, não foi possível observar uma associação estatisticamente significativa. Contudo, podemos perceber que nos pacientes que não possuem o gene de fusão EWS-FLI1, os níveis de expressão do gene ROCK1 são maiores do que em pacientes que possuem a translocação, com um valor de $p=0,06$ (Figura 8). 


\section{Expressão dos genes ROCK1 e ROCK2}

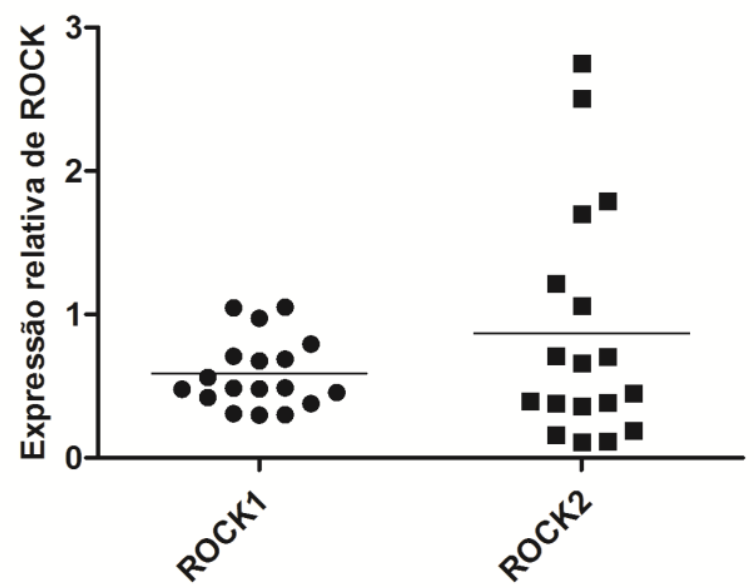

Figura 7: Expressão relativa dos genes ROCK1 e ROCK2 em amostras de pacientes com SE.

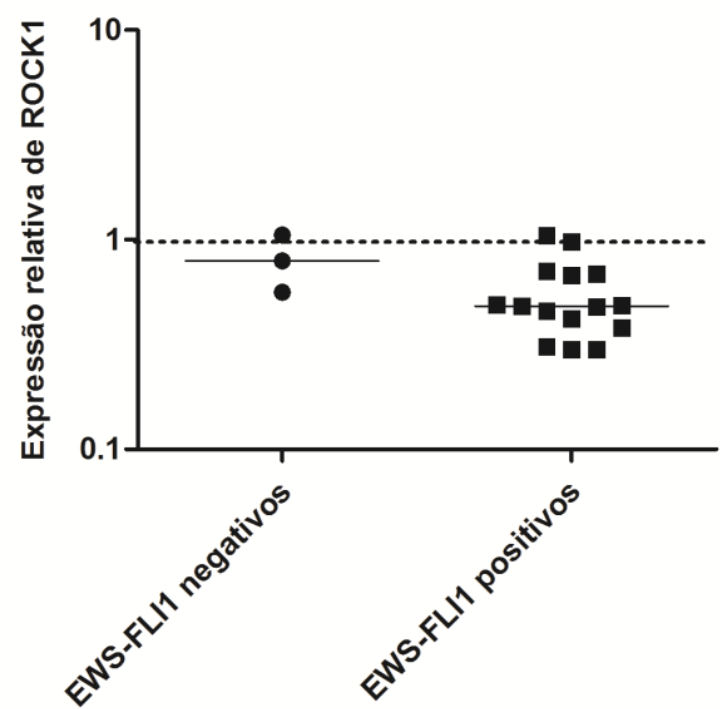

Figura 8: Expressão relativa do gene ROCK1 em pacientes negativos e positivos para o gene de fusão EWS-FLI1.

Uma análise de correlação entre as expressões dos genes ROCK1 e ROCK2 foi realizada através do programa SPSS, por meio do índice de correlação de Spearman, onde os dados das amostras tumorais foram utilizados. Os resultados mostram uma correlação positiva entre os genes ROCK1 e ROCK2 ( $\mathrm{p}=0,016, \mathrm{R}=0,495)$.

Análises de sobrevida também foram realizadas, tanto de Sobrevida Global (SG) quanto de Sobrevida Livre de Eventos (SLE) a partir do método de Kaplan-Meier. A SG trata-se do tempo decorrido entre o diagnóstico e o óbito do paciente, e a SLE é o tempo decorrido entre o diagnóstico e o acontecimento de algum evento como recidiva ou óbito. Apesar da associação com as expressões de ROCK1 e ROCK2 não ter sido estatisticamente significativa, pode-se perceber que menores níveis de expressão de ROCK1 e de ROCK2 aparentam estar relacionados com menor SG (Figura 9). 
- Expressão abaixo da mediana

- Expressão acima da mediana
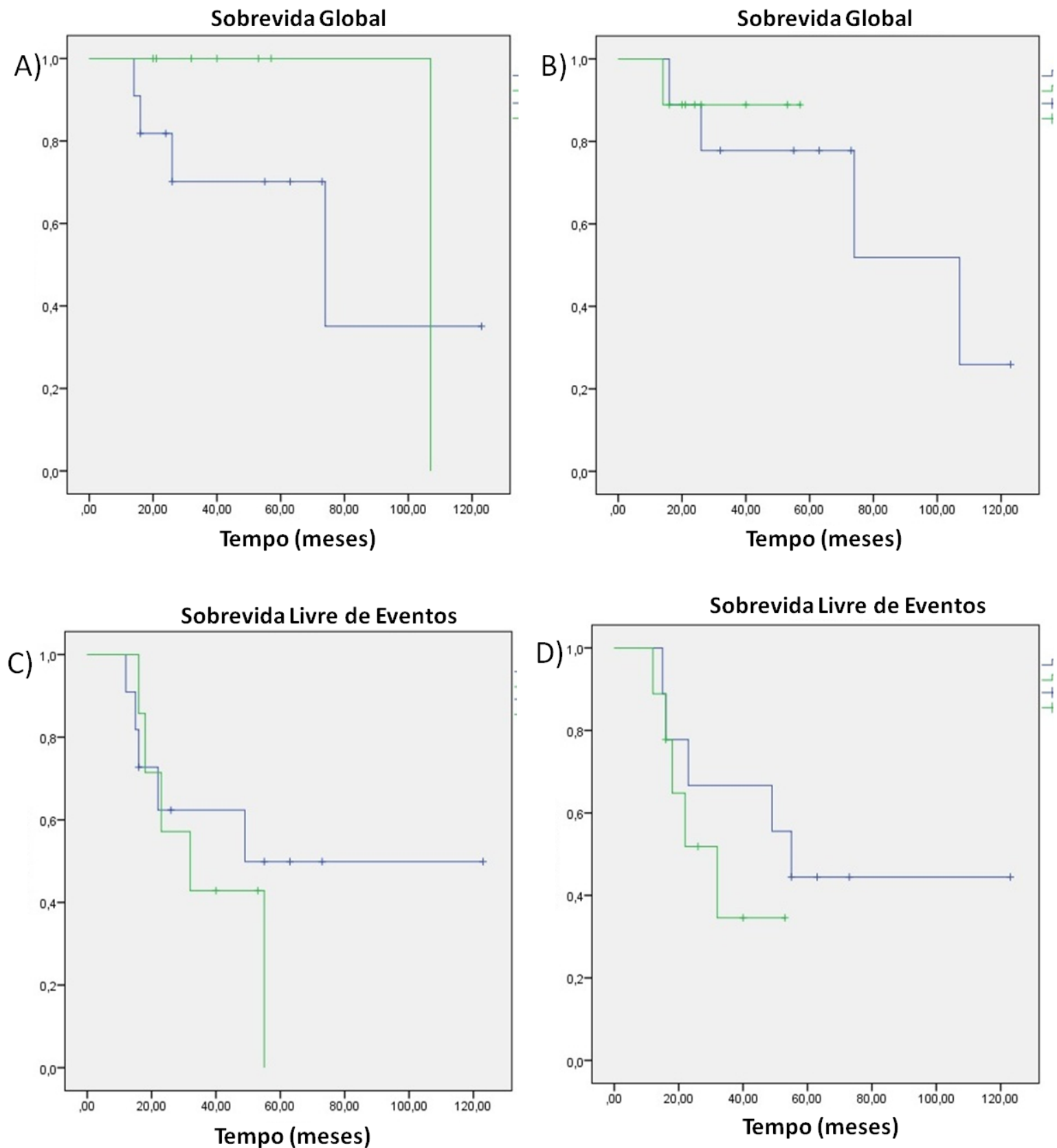

Figura 9: Curvas de Sobrevida Global (SG) e Sobrevida Livre de Eventos (SLE) e sua relação com níveis de expressão de ROCK1 (Figuras A e C) e ROCK2 (Figuras B e D). Os pacientes foram divididos em dois grupos: com expressões acima e abaixo da mediana. 


\subsection{Efeitos in vitro das drogas GSK429286, SR3677 e Hidroxifasudil}

\subsubsection{Proliferação celular}

As drogas GSK429286, SR3677 e Hidroxifasudil não alteraram estatisticamente a taxa de proliferação celular nas linhagens RD-ES e SK-ES-1 em nenhuma das doses, e em nenhum dos tempos estudados. Os resultados estão representados na Figura $\mathbf{1 0}$ em forma de gráficos com a média e o desvio padrão. Os testes foram realizados em quadruplicata, com três experimentos independentes.

SK-ES-1

A)

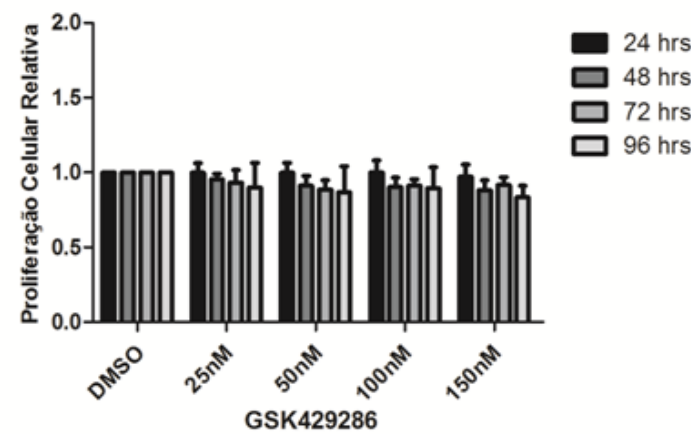

SK-ES-1

C

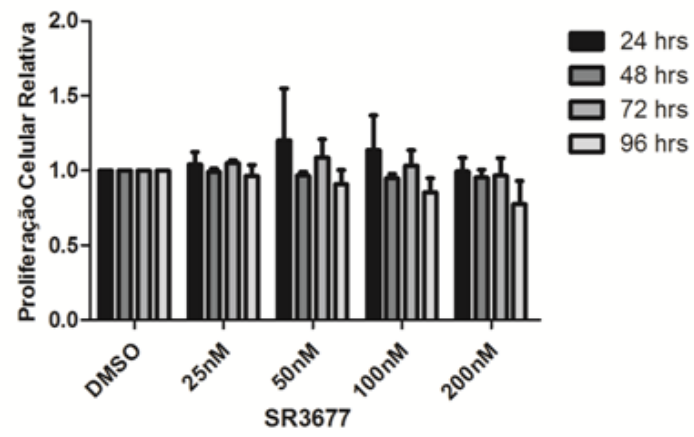

RD-ES

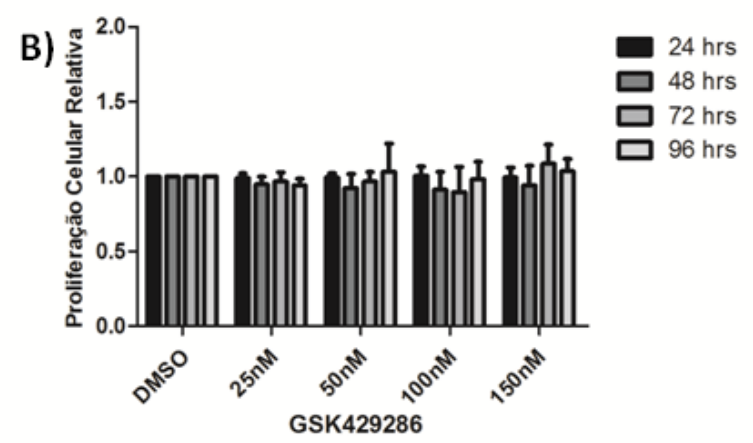

SK-ES-1

E)

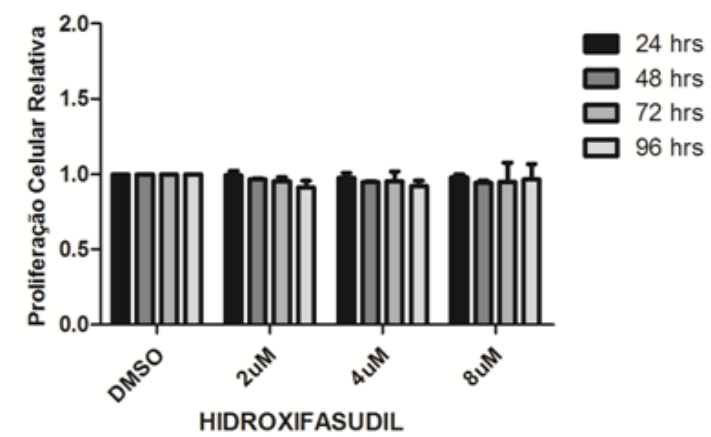

RD-ES

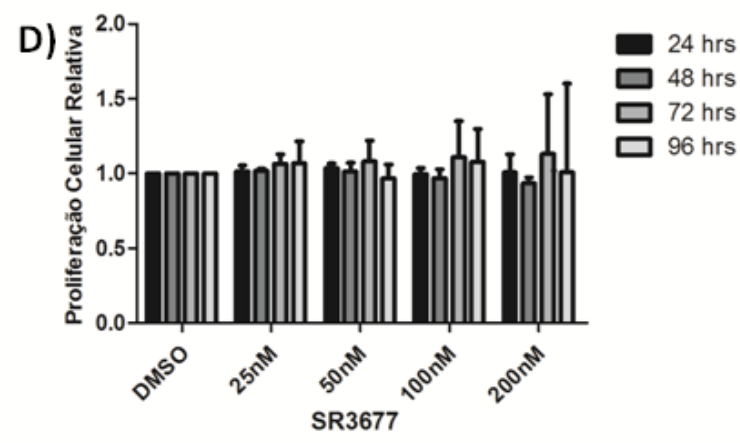

RD-ES

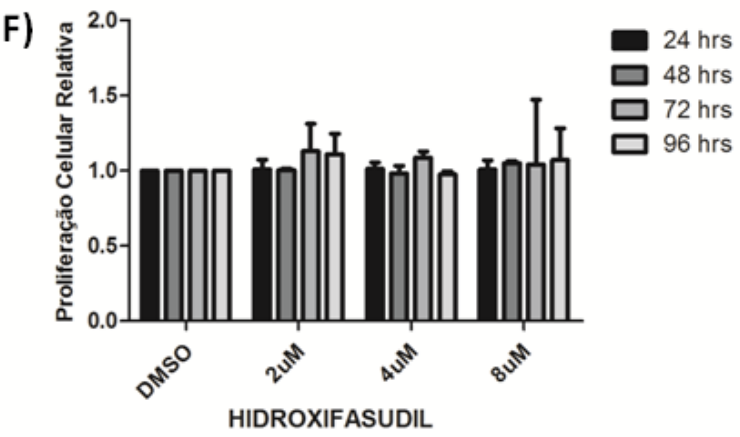

Figura 10: Análise da proliferação celular após o tratamento das linhagens SK-ES-1 e RD-ES com as drogas GSK429286 (Figuras A e B), SR3677 (Figuras C e D) e Hidroxifasudil (Figuras E e F), nos tempos de tratamento de $24,48,72$ e 96 h. 


\subsubsection{Capacidade clonogênica}

Para avaliar a capacidade das células formarem colônias após o tratamento com as drogas inibidoras de ROCK, foram utilizadas as concentrações de 50nM e 100 nM para GSK429286 e SR3677, $4 \mu \mathrm{M}$ e $8 \mu \mathrm{M}$ para Hidroxifasudil e o controle DMSO (veículo da droga) (Figura 11). Os ensaios foram realizados em duplicata, com três experimentos independentes e os gráficos representam a média e desvio padrão. A capacidade de formar colônias não foi alterada significativamente após o tratamento de $48 \mathrm{~h}$ com nenhum dos inibidores utilizados.

SK-ES-1

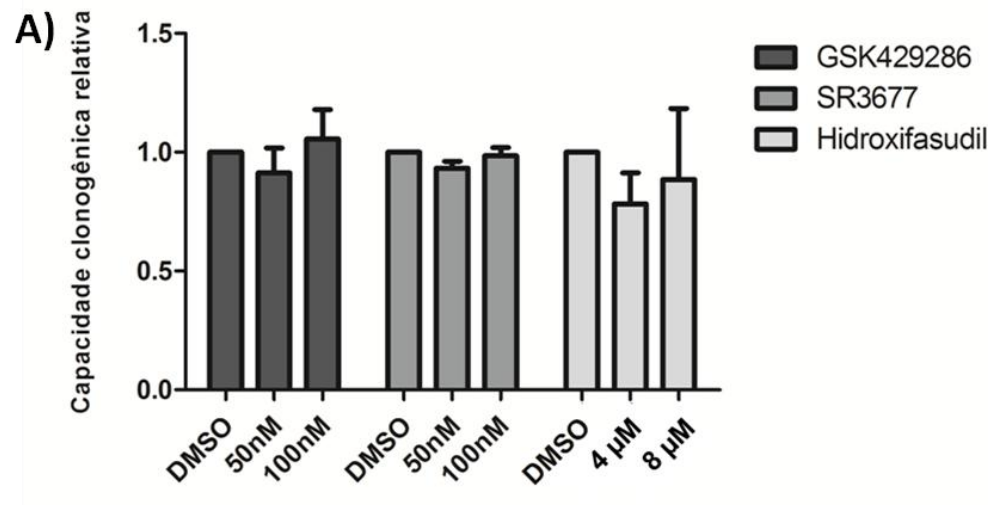

RD-ES

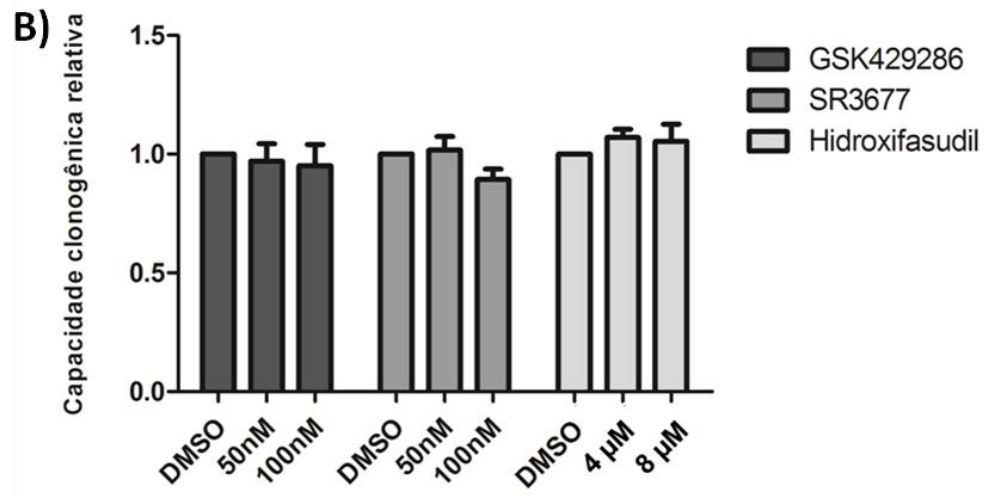

Figura 11: Análise da capacidade clonogênica das linhagens SK-ES-1 (Figura A) e RD-ES (Figura B) após 48 h de tratamento com as drogas GSK429286, SR3677 e Hidroxifasudil.

\subsubsection{Migração Celular}

A capacidade migratória das células foi testada após o tratamento com as drogas inibidoras de ROCK por meio do ensaio de migração por wound healing, após tratamento de $24 \mathrm{~h}$ com as drogas GSK429286, SR3677 e Hidroxifasudil nas mesmas concentrações das drogas utilizadas no ensaio de capacidade clonogênica. 
Os testes foram realizados em duplicata, com três experimentos independentes e o gráfico representa a média e desvio padrão. Apesar das alterações não serem estatisticamente significativas, pode-se perceber um tênue de aumento das taxas de migração da linhagem celular SK-ES-1 após tratamento de $24 \mathrm{~h}$ com as drogas GSK429286, SR3677 e Hidroxifasudil (Figura 12). Não foi possível realizar os experimentos de wound healing assay na linhagem celular RD-ES devido às suas características semi-aderentes.

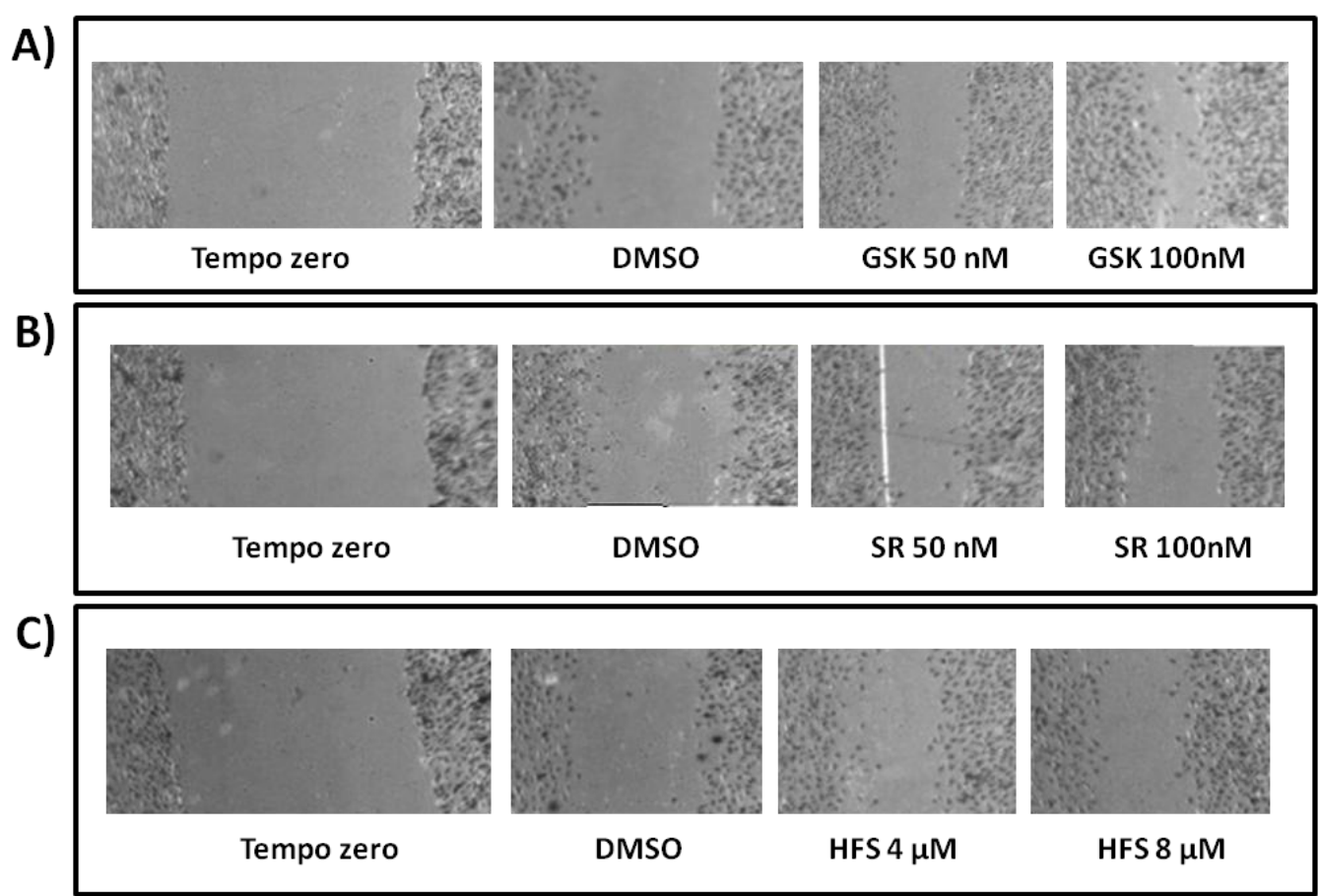

D)
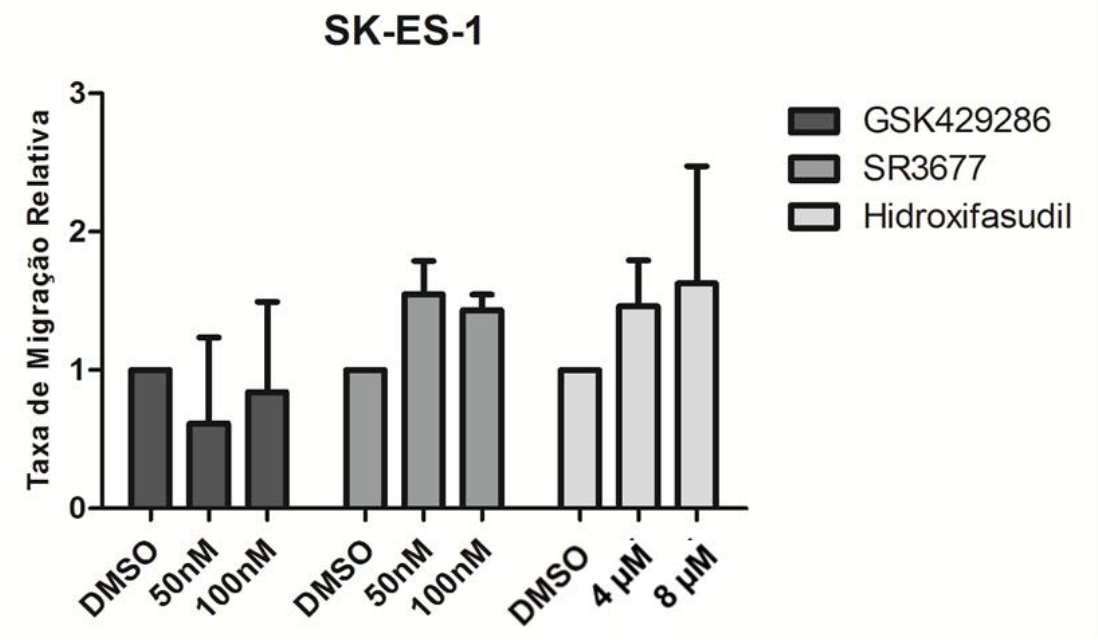

Figura 12: Análise da capacidade de migração da linhagem SK-ES-1 por meio de wound healing assay após $24 \mathrm{~h}$ de tratamento com as diferentes concentrações das drogas GSK429286 (Figura A), SR3677 (Figura B) e Hidroxifasudil (Figura C). O gráfico representa os valores de taxa de migração relativa mostrando a média e o desvio padrão em cada tratamento (Figura D). 


\subsubsection{Invasão Celular}

Para avaliar se a capacidade de invasão das células se altera após o tratamento com as drogas, o ensaio de invasão celular em matrigel foi conduzido após o tratamento de $24 \mathrm{~h}$ com as drogas de estudo. Foram realizados três experimentos independentes e o gráfico representa a média e desvio padrão (Figura 13). Assim como no ensaio de migração celular, embora as diferenças não tenham sido estatisticamente significantivas, podemos perceber que a invasão celular duplica após o tratamento de 24 h com as drogas GSK429286, SR3677 e Hidroxifasudil. Novamente, não foi possível realizar os experimentos de invasão com a linhagem celular RD-ES devido às suas características semi-aderentes. 
A)

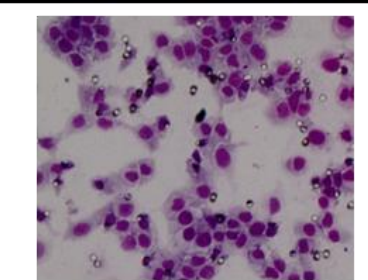

DMSO

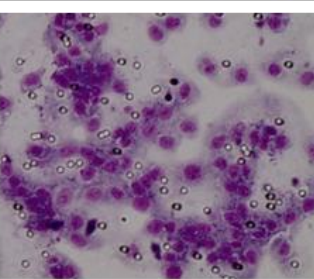

GSK $50 \mathrm{nM}$

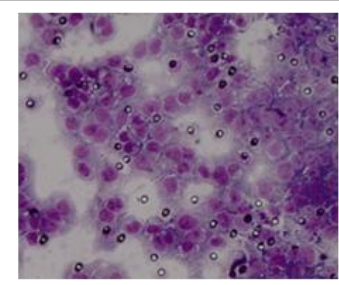

GSK 100nM

B)

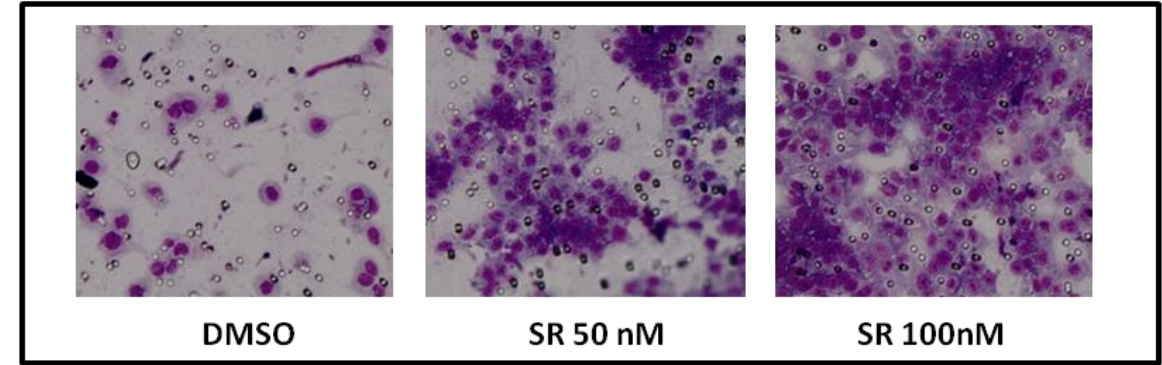

C)

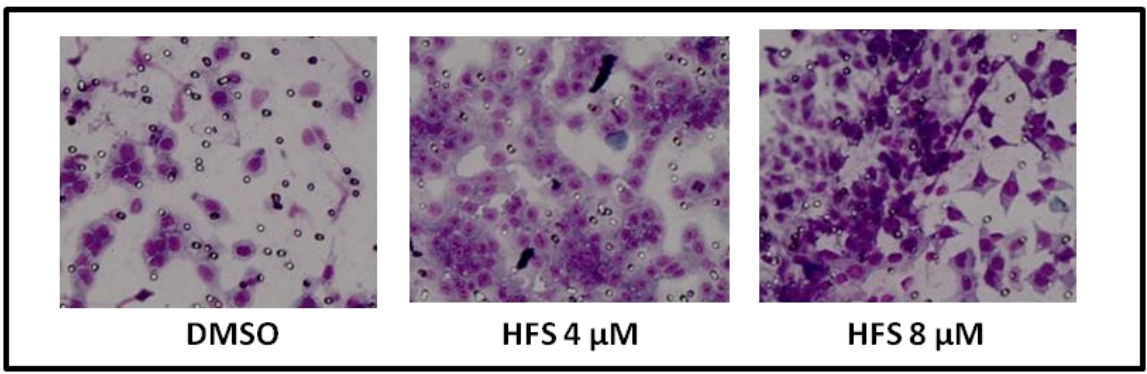

D)

SK-ES-1

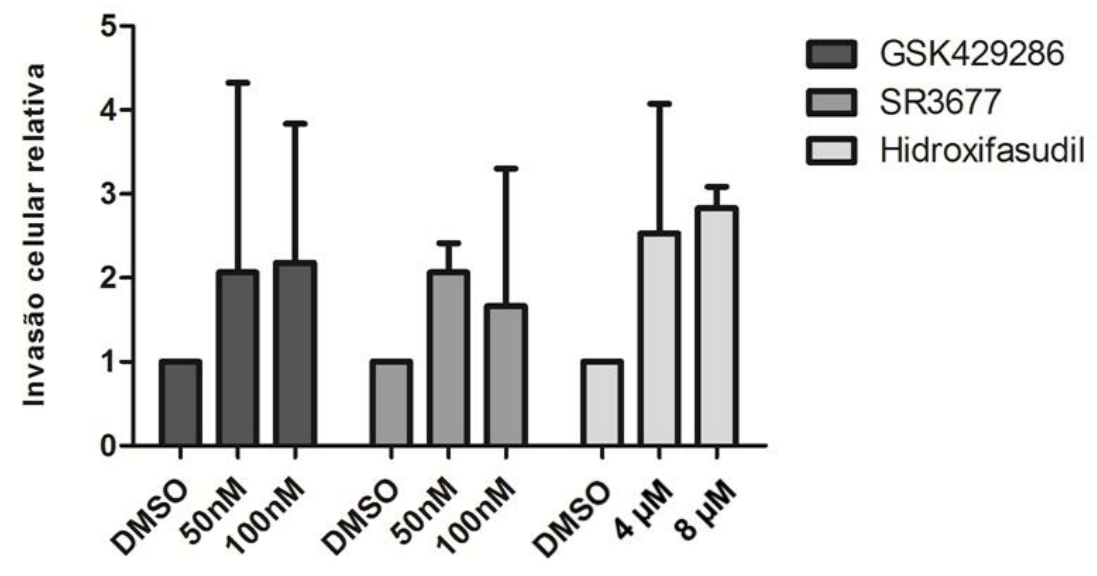

Figura 13: Análise da capacidade invasiva em matrigel da linhagem celular SK-ES-1 após 24 h de tratamento com as diferentes concentrações das drogas GSK429286 (Figura A), SR3677 (Figura B) e Hidroxifasudil (Figura C). O gráfico representa os valores de invasão celular relativa mostrando a média e o desvio padrão em cada tratamento (Figura D). 


\subsubsection{Ciclo Celular}

O ensaio para verificar possíveis alterações no ciclo celular também foi realizado após o tratamento de $24 \mathrm{~h}$ com as três drogas de estudo. Os ensaios foram realizados em duplicata, com três experimentos independentes com as linhagens SK-ES-1 e RD-ES. Os gráficos representam a média e desvio padrão. $\mathrm{O}$ ciclo celular não mostrou resultados estatisticamente significativos após tratamento com as drogas, quando comparados ao controle (Figuras 14 e 15).

\section{SK-ES-1}

A)

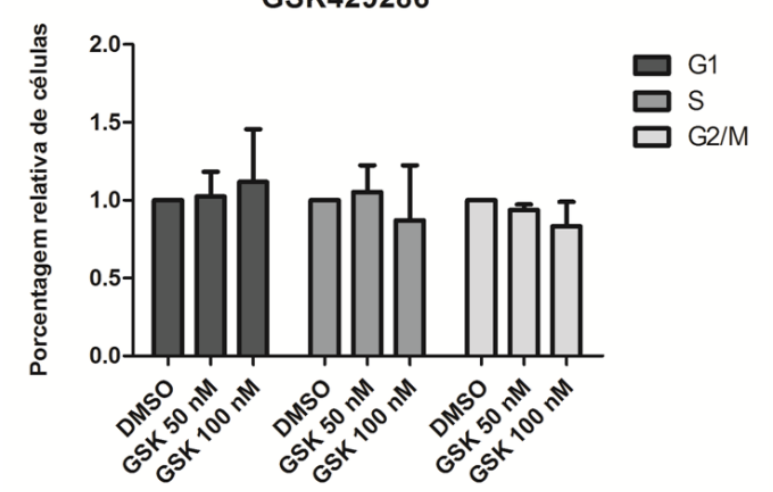

B)

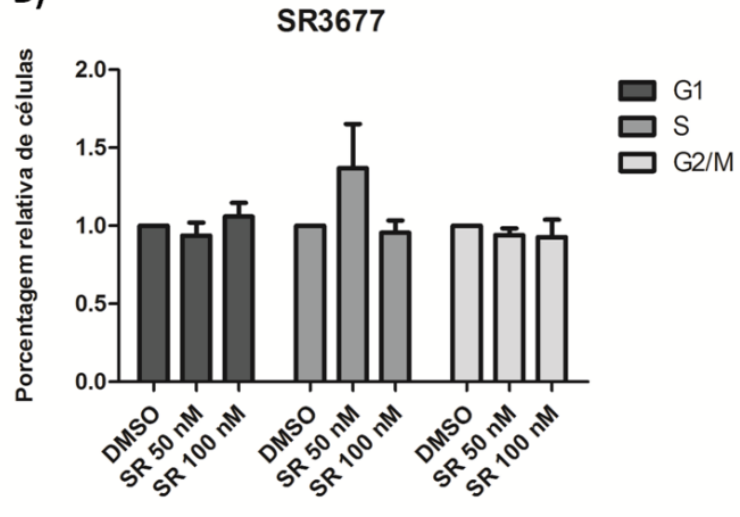

C)

Hidroxifasudil

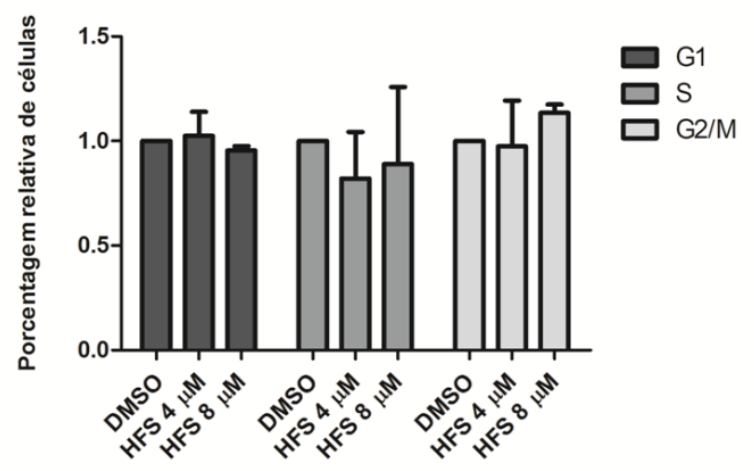

Figura 14: Análise do ciclo celular na linhagem celular SK-ES-1 após o tratamento de $24 \mathrm{~h}$ com as diferentes concentrações das drogas GSK429286 (Figura A), SR3677 (Figura B) e Hidroxifasudil (Figura C). 


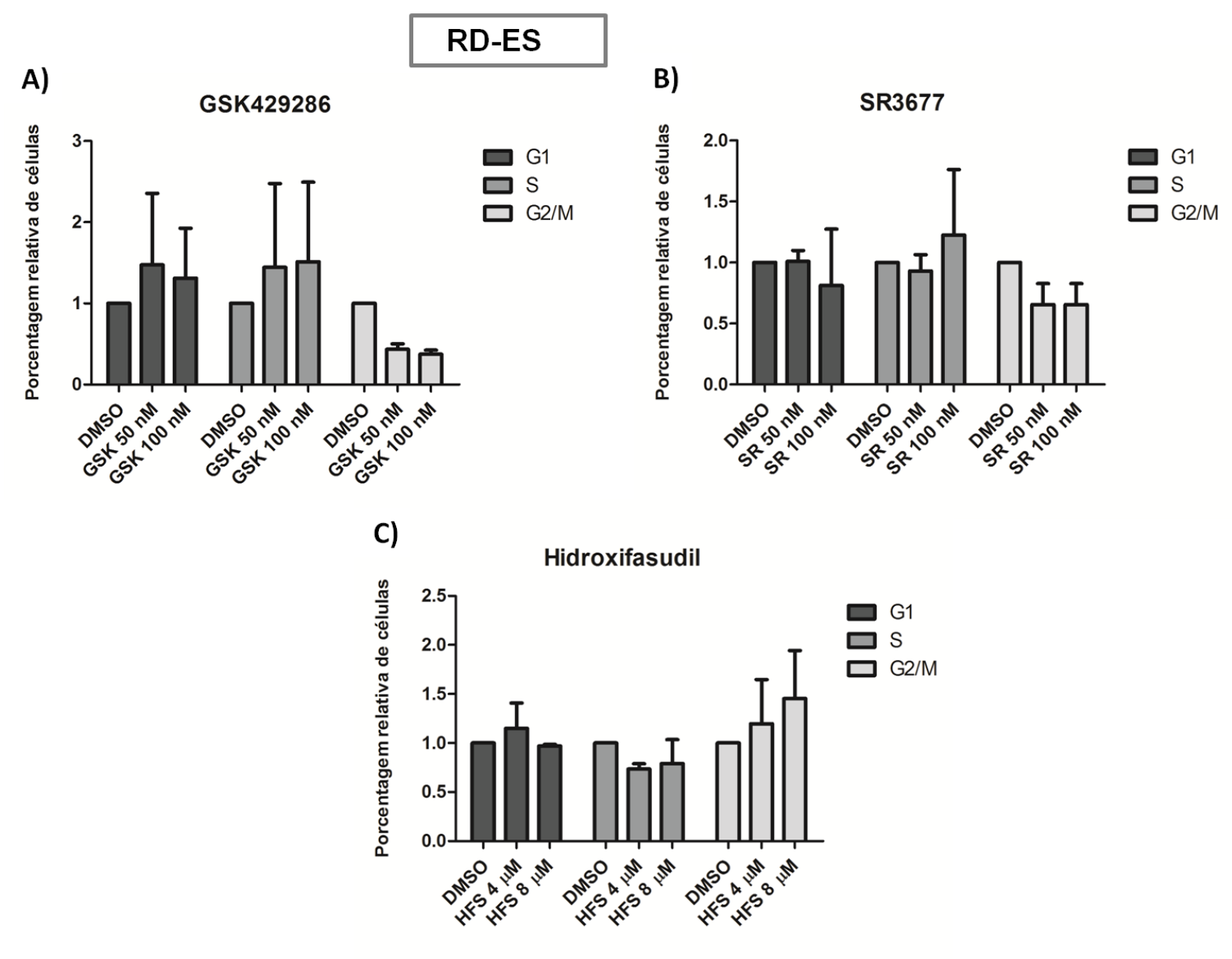

Figura 15: Análise do ciclo celular na linhagem celular RD-ES após o tratamento de $24 \mathrm{~h}$ com as diferentes concentrações das drogas GSK429286 (Figura A), SR3677 (Figura B) e Hidroxifasudil (Figura C). 
Discuessãa 
O SE é o segundo tumor ósseo maligno mais comum em crianças e adolescentes, acometendo 3 em cada 1 milhão de crianças por ano. Apesar dos tratamentos proporcionarem melhora na sobrevida dos pacientes com SE localizado, nos últimos anos as estratégias de tratamento não obtiveram avanços. $60 \%$ a $70 \%$ dos pacientes com a doença localizada atingem a sobrevida de 5 anos, porém, em pacientes com a doença recorrente ou os que apresentam metástase no momento do diagnóstico essa taxa de sobrevida cai para 10\% a 40\% (Ladenstein et al., 2010; Sand et al., 2015). A metástase, portanto, possui grande influência no prognóstico dos pacientes com SE, e é uma característica que está associada a um pior prognóstico, sendo necessária a melhor compreensão deste mecanismo para que seja possível a busca de alvos terapêuticos mais eficientes e específicos para esta doença.

A metástase, juntamente com eventos que envolvem a transformação celular, crescimento tumoral, neovascularização e invasão, são etapas necessárias para que ocorra a iniciação e progressão do câncer (Wei et al., 2015). Para que a metástase tumoral aconteça, as células precisam adquirir certas características e passar por diversos processos, como o desprendimento de suas células vizinhas, migração e invasão de tecidos e vasos sanguíneos e a adesão em um sítio secundário onde irá se proliferar e colonizar (Ginsberg et al., 2001; Schroeder et al., 2012).

A migração pode ocorrer tanto da forma coletiva, como da forma individual, sendo que a forma individual pode ser do tipo ameboide ou mesenquimal, dependendo do microambiente em que as células estão presentes (Ginsberg et al., 2001). O tipo de migração ameboide é mediado pela proteína RhoA e suas efetoras ROCK1 e ROCK2, que também estão relacionadas a processos como proliferação celular, adesão, apoptose e citocinese (Croft \& Olson, 2008; Julian \& Olson, 2014). Diversos trabalhos relatam que a sinalização da via Rho/ROCK possui funções na carcinogênese (Wei et al., 2015). As proteínas ROCK, portanto, podem ser consideradas importantes alvos na busca de novas terapias.

No presente trabalho, foi estudada a expressão dos genes que codificam as proteínas ROCK e observou-se que os genes ROCK1 e ROCK2 estão desregulados em amostras de pacientes com $\mathrm{SE}$, estando hipoexpressos quando comparados com ambas as amostras controles (amostras de osso não neoplásico e linhagens primárias de osteoblasto). Nas linhagens celulares SK-ES-1 e RD-ES estes genes também foram encontrados hipoexpressos quando comparados às linhagens de osteoblasto, porém não houve diferença estatisticamente significativa quando comparados às amostras de osso não neoplásico.

Esta diferença encontrada entre as amostras controle pode ser devido ao nível de diferenciação e composição diferentes quando comparamos tecido ósseo e osteoblastos. O osso é um tecido dinâmico, que sofre modificações conforme a idade e localização, além de possuir uma composição bem heterogênea e um maior nível de diferenciação (Kartsogiannis et al., 2004). Diferentemente, as 
células de osteoblastos não possuem tanta variação na composição, e são mais indiferenciadas. Essa menor heterogeinidade e diferenciação dos osteoblastos podem refletir em um menor nível de variação da expressão dos genes ROCK1 e ROCK2, o que pôde ser observado nas nossas análises, conforme mostrado nas Figuras 5 e 6.

As células de SE são embrionárias e de origem mesenquimal. Neste tumor, há uma desregulação na diferenciação dos osteoblastos caracterizada pela diferenciação interrompida dos mesmos e uma proliferação descontrolada, mantendo as células tumorais num estado indiferenciado (Marie et al., 2014). Tendo em vista todos estes fatores, embora também existam registros na literatura mostrando a utilização de amostras de osso normal como controle do SE (Li et al., 2008; Sarver et al., 2015), a utilização de osteoblastos é mais abrangente e se mostra como um controle mais apropriado do que as amostras de osso não neoplásico (Valen et al., 2003; Zhou et al, 2013; Bonilla et al, 2015).

Os dados de expressão gênica possuem grande relevância, uma vez que ainda não haviam sido registrados na literatura estudos de expressão dos genes ROCK1 e ROCK2 em SE. Além disso, na maioria dos tumores já estudados, estes genes encontram-se hiperexpressos quando comparados às aos controles, indicando possíveis diferenças no comportamento deste tumor em relação a estas proteínas (Kamai, 2003; Lane et al., 2008; Babeto et al., 2011; Liu et al., 2011; Yong-Jun et al., 2014; Zhang et al., 2015).

Foram avaliados também, os dados clínicos dos pacientes com SE (idade, sexo, cor, tamanho e local do tumor, grau de necrose, presença de metástase, recidiva e do gene de fusão EWS-FLI1) verificando uma possível relação entre eles e os níveis de expressão de ROCK1 e ROCK2. Nenhuma relação estatisticamente significativa foi encontrada. Contudo, podemos observar que em pacientes negativos para o gene de fusão EWS-FLI1, os níveis de expressão de ROCK1 são maiores do que naqueles que são positivos para este gene de fusão. Os pacientes estudados que não possuem o gene de fusão EWS-FLI1, possuem outras translocações que ocorrem em SE que não foram estudadas neste trabalho. Podemos observar também, que nossos dados de frequência do gene EWS-FLI1 nos pacientes estudados corroboram com a literatura, uma vez que de 18 pacientes, 15 apresentaram esta translocação, ou seja, 83\% (Aurias et al., 1983; Turc-Carel et al, 1988).

O gene EWS-FLI1 é um fator de transcrição quimérico que possui como alvo muitos genes envolvidos em processos como diferenciação, sobrevivência e carcinogênese do SE. O EWS-FLI1 pode reprimir ou induzir a transcrição destes genes através do mecanismo de abertura da cromatina e recrutamento de metiltransferases e acetiltransferases que regulam a expressão gênica, como já descrito por Riggi et al. (2014). Dentre os genes regulados positivamente por este fator de transcrição estão o proto-oncogene $D E K$ e o gene SOX2, envolvido na regulação do desenvolvimento embrionário e que possui um importante papel na diferenciação e patogênese na FTE. O gene TGFB1, 
um regulador de crescimento celular e diferenciação, é um exemplo dos genes que EWS-FLI1 reprime a transcrição (Riggi et al., 2010; 2014).

Já foi demonstrada uma relação entre o gene SOX2 e a via Rho/ROCK em linhagens celulares de glioblastoma, onde células knockdown para SOX2 demonstraram um aumento de RhoA e uma diminuição dos níveis de CiclinaD1. Li et al. (2006) já descreveram a CiclinaD1 como um inibidor de RhoA/ROCK em fibroblastos embrionários de camundongos. Similarmente, Wang et al. (2013) demonstraram que em linhagens celulares de câncer de pulmão a depleção do gene DEK leva a diminuição dos níveis gênicos e proteicos de RhoA e a desativação da via RhoA/ROCK/MLC.

Em culturas primárias de condrócitos do acetábulo de ratos com displasia do quadril, o gene TGF61 está hiperexpresso e estimulando a via de ROCK1, que por sua vez regula a organização do citoesqueleto, morfologia celular e diferenciação dos condrócitos (Pei et al., 2014). Manickman et al. (2014) também descreveram a relação do gene TGFB1 e a via de ROCK em linhagens celulares de miofibroblasto de rim, onde TGFB1 estimulou a via RhoA-GTP ativa e a expressão de ROCK, e estes dados foram confirmados pela inibição de RhoA por siRNA e de ROCK pela droga Y-27632, que diminuiu os níveis de TGFB1.

Estes mesmos mecanismos podem ocorrer nas células tumorais de SE estudadas neste trabalho. Isso pode explicar o fato de que quando o gene EWS-FLI1 está ausente, os níveis de SOX2 e/ou DEK estão diminuídos e/ou TGFB1 aumentados e consequentemente a expressão de ROCK1 aumentada. Esta relação pode explicar ainda, a hipoexpressão de ROCK1 e ROCK2 nas linhagens celulares de SE analisadas e na maioria das amostras tumorais, uma vez que estas possuem o gene de fusão EWSFLI1, podendo possuir altos níveis de SOX2 e/ou DEK e/ou baixos níveis de TGF61, levando a baixos níveis de RhOA, ROCK1 e ROCK2. Entretando, para confirmar estas hipóteses, a expressão de SOX2, CiclinaD1, DEK e TGFB1 devem ser analisados nestas linhagens e em amostras tumorais, bem como suas relações com ROCK1 e ROCK2 neste tipo tumoral.

Outros parâmetros analisados foram a sobrevida global (SG) e a sobrevida livre de eventos (SLE) dos pacientes, tentando encontrar uma associação com a expressão diferencial de ROCK1 e ROCK2. Apesar das associações não serem estatisticamente significativas, pode-se perceber que menores níveis de expressão de ROCK1 e de ROCK2 aparentam estar relaciondados com menor sobrevida global. Liu et al. (2011), demonstraram correlação negativa entre ROCK1 e menor sobrevida global de pacientes com osteosarcoma, que também é um sarcoma ósseo. Similar ao presente trabalho, YongJun et al. (2014) não encontraram associação do sexo com expressão de ROCK1 em carcinoma gástrico, mas encontraram associação entre altos níveis de expressão e metástase, assim como com pior prognóstico. Contudo, outros autores não encontraram correlação com idade, sexo, localização do tumor e tipo tumoral, corroborando com os dados deste trabalho. 
Quanto a ROCK2, alguns autores correlacionaram sua elevada expressão com grau histológico e metástases linfonodais em câncer cervical, mas não com a idade e estágio clínico (Ying \& Zhang, 2012). Do mesmo modo, Zhang et al. (2015) demonstraram em carcinoma de células escamosas da laringe que a alta expressão de ROCK1 está associada com o tamanho do tumor e com metástases, assim como a alta expressão de ROCK2 associada com o tamanho do tumor e diferenciação. Entretanto, os mesmos autores não encontraram associação entre a expressão de ROCK com estágio clínico, recidiva ou sobrevida.

A ausência de associações estatísticas significantes neste estudo, pode ser também consequência do número relativamente baixo de amostras, que quando separadas entre os subgrupos de acordo com as características clínicas (por exemplo, grau baixo ou alto de necrose, presença ou ausência de recidiva, etc) se tornam ainda mais reduzidas, dificultando a análise. Além disso, houve a perda de seguimento de alguns pacientes, não sendo possível ter todos os dados clínicos de todos, diminuiundo ainda mais este número.

Por outro lado, devido a todas as funções atribuídas às proteínas ROCK e suas relações na tumorigênese e prognóstico de diversos tumores, inibidores de ROCK têm sido amplamente descritos como possíveis antitumorais. Estas moléculas afetam processos como crescimento, invasão e migração dos mais variados tipos tumorais, além de já terem sido descritos como potencializadores da eficácia de agentes quimioterápicos e da radioterapia (Chin et al., 2015).

Fujimura et al. (2015) por meio de intervenção genética e farmacológica do gene elF5A (eukaryotic translation initiation factor $5 A$ ) inibiu RhoA/ROCK2 e observou a diminuição da invasão, migração e metástase in vivo em adenocarcinoma ductal pancreático, descrevendo ainda que este mecanismo ocorre porque o gene eIF5A regula RhOA e ROCK2 pós transcricionalmente.

Patel et al. (2014) também demonstraram que um inibidor de ROCK (RKI-18) inibiu migração, invasão e crescimento independente de ancoragem em linhagens celulares de câncer de mama. Também em câncer de mama, Hsu et al. (2015) detectaram por imunohistoquímica uma associação entre a presença de ROCK2 nuclear com metástase e com pior prognóstico de pacientes com câncer de mama.

Zhang et al. (2015) demonstraram que a substância Incarvina C, um alcaloide extraído de uma planta medicinal chinesa, causa diminuição da proliferação e migração celular, aumento na apoptose e uma parada do ciclo celular na fase G1 em linhagem celular de carcinoma hepatocelular, através da inibição da via Rho/ROCK.

Tendo em vista inúmeros bons resultados com a inibição de ROCK e considerando que mesmo os genes ROCK estando hipoexpressos nas linhagens celulares de SE quando comparados aos controles normais, sabe-se que ROCK é ubiquamente expressa nos tecidos, havendo expressão de ROCK nas 
linhagens, ainda que seja menor do que nas células normais. Portanto, decidiu-se estudar neste trabalho os efeitos da inibição das proteínas ROCK nas linhagens celulares de SE.

As drogas utilizadas no presente trabalho foram GSK429286 e SR3677 que são inibidoras específicas de ROCK1 e ROCK2, respectivamente, e Hidroxifasudil que é um pan-inibidor, inibindo ROCK1 e ROCK2 concomitantemente. Todas as drogas já foram descritas por possuir alta eficácia e por agirem no sítio de ATP das proteínas ROCK, impedindo que as proteínas fosforilem seus alvos (Goodman et al., 2007; Feng et al., 2008; Wei \& Malhotra, 2010).

Inicialmente, foi realizado o ensaio de proliferação celular com duas diferentes linhagens celulares de $\mathrm{SE}$, com as doses indicadas na literatura como seus $\mathrm{IC}_{50}$, porém não houve alterações significativas nas taxas de proliferação (dados não apresentados). Mesmo aumentando as doses até 100nM no caso da GSK429286 e SR3677 e $8 \mu \mathrm{M}$ no caso da Hidroxifasudil, não foi encontrado nenhum resultado estatisticamente significativo. O mesmo ocorreu no ensaio de capacidade clonogênica e de análise de ciclo celular, que não obtiveram alterações significativas após tratamento com as drogas.

Esta ausência de alteração significativa após tratamento com as drogas pode ser consequência da hipoexpressão de ROCK1 e ROCK2, ou simplesmente pelo fato de que diferentes tipos celulares respondem a drogas de formas distintas. Chapman et al. (2014) também utilizaram doses mais altas (100nM) da droga GSK429286 em queratinócitos para inibir a proteína ROCK1. Este mesmo trabalho utilizou diferentes inibidores de ROCK e constatou que em queratinócitos, esta inibição estimulou a expressão de genes relacionados a ciclo celular, replicação e divisão celular.

Os ensaios de migração e invasão celular também foram realizados com a linhagem SK-ES-1. Novamente, os resultados não apresentaram alterações significativas, porém, há um tênue aumento da migração e invasão na linhagem celular após o tratamento com as drogas, que pode ser observado nas Figuras 12 e 13. A ausência de resultados estatisticamente significativos pode ser consequência do alto desvio padrão encontrado nos ensaios. Contudo, é possível perceber que as drogas alteram o comportamento migratório e invasivo das células, diferente do que ocorre nos ensaios de proliferação celular e capacidade clonogênica, que não sofreram alteração sob o tratamento com as drogas.

Como já comentado, a via Rho/ROCK possui importante papel na migração e invasão celular, principalmente quando se trata da migração ameboide, que é controlada por Rho. Vigil et al. (2012) suprimiu a expressão de ROCK com uma molécula inibidora sintética e com siRNA em linhagens celulares de carcinoma pulmonar de células não pequenas e demonstrou que o crescimento independente de ancoragem e a invasão em matrigel são dependentes de ROCK, diferente do crescimento dependente de ancoragem. Sendo assim, o ensaio de invasão em matrigel representa bem a invasão dependente de ROCK. 
Entretanto, como já discutido, a hipoexpressão dos genes ROCK1 e ROCK2 nas amostras tumorais e linhagens celulares de SE podem explicar este efeito adverso da inibição das proteínas ROCK1 e ROCK2 na proliferação celular, migração, invasão celular e capacidade clonogênica. Segundo Julian \& Olson (2014), a atividade de ROCK pode promover a proliferação em alguns tipos celulares assim como pode igualmente ter papel anti-proliferativo em outros, citando como exemplo a inibição de ROCK em queratinócitos humanos que resulta no aumento da proliferação celular e diminuição da diferenciação celular.

Vários autores demonstraram que a inibição da via de ROCK diminui a proliferação, migração e invasão celular em diferentes tumores. Reymond et al. (2015) citam a via RhoC/ROCK como um forte candidato a alvo terapêutico para redução de metástase a partir da interação com células endoteliais. Sun et al. (2014) encontraram a atenuação da via RhoA/ROCK/MMPs a partir do tratamento com curcumina em linhagem celular de câncer de mama, inibindo assim a invasão celular. O inibidor específico de ROCK, Y27632, reduziu a capacidade de migração e invasão de linhagens celulares de carcinoma hepatocelular, de forma dose dependente (Zhang et al., 2014). Similarmente, em linhagens celulares de câncer de próstata, Kroiss et al. (2014) encontraram a diminuição da migração e invasão celular por meio da transfecção do microRNA-135a, que diminuiu a expressão das proteínas ROCK1 e ROCK2.

Por outro lado, Abe et al. (2014) utilizou o inibidor de ROCK HA-1077 e verificou que após o tratamento, a proliferação celular e a migração aumentaram em linhagens celulares de tumor urotelial, assim como ocorreu a indução de apoptose. Outro trabalho recente (Tilson et al., 2015) utilizou os inibidores de ROCK Y27632 e Fasudil em linhagens de células tronco tumorais de glioblastoma (GSCs) e verificou a inibição da apoptose e o aumento na formação de esferas tumorais, facilitando a expansão das GSCS.

Demonstrando resultados congruentes com estes efeitos adversos de ROCK nas células, Mertsch e Thanos (2014) testaram a migração celular em células knockdown para ROCK1 e ROCK2 e encontraram diferentes efeitos na deleção de ROCK1 e ROCK2: a deleção de ROCK1 diminuiu a migração celular e a deleção de ROCK2 aumentou a migração celular. Quanto à proliferação celular, a deleção de $R O C K 1$ levou a uma diminuição da proliferação, ao contrário da deleção de $R O C K 2$, que resultou num aumento da proliferação celular. Estes autores também concluíram que ROCK1 é dependente de substrato, enquanto a ROCK2 é independente.

Portanto, é evidente que as proteínas ROCK1 e ROCK2 exercem diferentes funções nos diferentes tipos tumorais devido as suas inúmeras interações e funções nas células. Isso pode explicar os dados obtidos nestes ensaios, uma vez que a maioria dos tipos tumorais já estudados apresenta uma hiperexpressão de $R O C K$ em relação às amostras controles, diferente das amostras tumorais e linhagens de SE aqui estudadas, que se mostraram hipoexpressas. Entretanto, o trabalho 
mostrou que pode haver uma relação entre a presença do gene de fusão EWS-FLI1, que é um importante e frequente oncogene do SE, e o gene ROCK1. Além disso, os dados demonstram que as proteínas ROCK podem não estar relacionadas com o prognóstico dos pacientes e com os processos de proliferação e capacidade clonogênica em SE, mas podem estar associadas com a migração e invasão celular. Estudos aprofundados a nível gênico e proteico das vias relacionadas com cada mecanismo celular e com a via Rho/ROCK são necessários para se estabelecer as exatas funções das proteínas ROCK1 e ROCK2 no SE. 
Bancluséres 
Os resultados deste trabalho permitiram concluir que:

- Há uma desregulação tanto do gene ROCK1 quanto do gene ROCK2 nas amostras tumorais e linhagens celulares de SE estudadas, estando hipoexpressos quando comparados aos controles;

- Os genes ROCK1 e ROCK2 não demonstraram associação com prognóstico ou sobrevida;

- A presença do gene de fusão EWS-FLI1 parece estar associada com menores níveis de expressão de ROCK1, porém o estudo necessita ser realizado numa coorte maior para confirmação dos dados;

- O estudo da inibição das proteínas ROCK1 e ROCK2 demonstrou que a proliferação celular, a capacidade clonogênica, a capacidade migratória, a capacidade invasiva e o ciclo celular não se alteram significativamente comparadas ao controle após o tratamento com as drogas GSK429286, SR3677 e Hidroxifasudil nas linhagens de SE estudadas. No entanto, a inibição com tais drogas pareceu aumentar a taxa de migração e invasão celular, necessitando, porém, novos estudos para confirmarem estes dados. 
Oreferências

Bibliagráficas 
Abe, H., Kamai, T., Hayashi, K. et al. The Rho-kinase inhibitor HA-1077 suppresses proliferation/migration and induces apoptosis of urothelial cancer cells. BMC Cancer, v. 14, n. 412, 2014.

AC Carmargo, Cancer Center. Disponível em: <http://www.accamargo.org.br/tudo-sobre-ocancer/sarcoma-de-ewing/36/> . Acesso em março de 2016.

Amin, E., Dubey, N., Zhang, S., Gremer, L., Dvorsky, R., Moll, J. M., Taha, M. S., Nagel-Steger, L., Piekorz, R. P., Somlyo, A. V., Ahmadian, M. R.. et al. Rho-kinase: regulation, (dys)function, and inhibition. Biol. Chem. v. 394, n. 11, p. 1399-1410, 2013.

Aurias A., Rimbaut C., Buffe D., Dubousset J., Mazabraud, A. Translocation of chromosome 22 in Ewing's sarcoma. C R Seances Acad Sci III, v. 296, n. 23, p. 1105-1107, 1983.

Babeto, E., Conceição, A. L., Valsechi, M. C., Peitl, J. P., Zuccari, D. A. C., Lima, L. G., Bonilha, J. L., Calmon, M. F., Cordeiro, J. A., Rahal, P. Differentially expressed genes in giant cell tumor of bone. Virchows Arch, v. 458, n. 4, p. 467-476, 2011.

Bernstein, M., Kovar, H., Paulussen, M., Randall, R. L., Schuck, A., Teot, L. A, Juergens, H. Ewing's sarcoma family of tumors: current management. The Oncologist, v. 11, n. 5, p. 503-519, 2006.

Bonilla, X., Dakir, E., Mollinedo, F., Gajate, C. Endoplasmic reticulum targeting in Ewing's sarcoma by the alkylphospholipid analog edelfosine. Oncotarget. V. 6, n. 16, p. 14596-14613, 5.

Chapman, S., Mcdermott, D.H., Shen, K., Jang, M.K., Mcbride, A.A. The effect of Rho kinase inhibition on long-term keratinocyte proliferation is rapid and conditional. Stem Cell Research \& Therapy, v. 5, n. 60, 2014.

Chin, V. T., Nagrial, A. M., Chou, A., Biankin, A. V., Gill, A. J., Timpson, P., Pajic, M. Rho-associated kinase signalling and the cancer microenvironment: novel biological implications and therapeutic opportunities. Expert Reviews in Molecular Medicine, v. 17; e17; p. 1 - 14, 2015.

Croft, D.R. \& Olson, M.F. (2008). Regulating the Conversion between Rounded and Elongated Modes of Cancer Cell Movement. Cancer Cell, v. 14, p. 349-351, 2008. doi: 10.1016/j.ccr.2008.10.009.

Delattre, O., Zucman, J., Desmaze, B. P. C., Melot, T., Peter, M., Kovar, H., Joubert, I., Jong, P., Rouleau, G., Aurias, A., Thomas, G. Gene fusion with na ETS DNA-binding domain caused by chromossome translocation in human tumours. Nature, v. 359, p. 162-165, 1992.

Demicco E.G., Maki R.G., Lev D.C., Lazar A.J. New therapeutic targets in soft tissue sarcoma. $A d v$ Anatomy Pathology, v. 19, n. 3, p. 170-80, 2012.

Dvorsky, R., Blumenstein, L., Vetter, I. R., Ahmadian, M. R. Structural insights into the interaction of ROCKI with the switch regions of RhoA. The Journal of Biological Chemistry, v. 279, n. 8, p. 7098-104, 2004.

Erkizan H.V., Uversky V.N., Toretsky J.A. Oncogenic partnerships: EWS-FLI1 protein interactions initiate key pathways of Ewing's sarcoma. Clinical Cancer Research, v. 16, n. 16, p. 4077-4083, 2010.

Feng, Y., LoGrasso, P. V., Defert, O., Li, R. Rho Kinase (ROCK) Inhibitors and Their Therapeutic Potential. Journal of Medicina Chemistry, 2015. doi: 10.1021/acs.jmedchem.5b00683. 
Feng, Y., Yin, Y., Weiser, A., Griffin, E., Cameron, M. D., Lin, L., Ruiz, C., Schürer, S. C., Inoue, T., Rao, P. V., Schröter, T., Lograsso, P. Discovery of Substituted 4-(Pyrazol-4-yl) phenylbenzodioxane-2carboxamides as Potent and Highly Selective Rho Kinase (ROCK-II) Inhibitors. J. Med. Chem., v. 51, p. 6642-6645, 2008.

Ferreira, B. I., Alonso J., Carrillo J., Acquadro F, Largo C, Suela J, Teixeira MR, Cerveira N, Molares A, Goméz-López G, Pestaña A, Sastre A, Garcia-Miguel P,Cigudosa JC. Array cgh and gene-expression profiling reveals distinct genomic instability patterns associated with DNA repair and cell-cycle checkpoint pathways in ewing's sarcoma. Oncogene, v. 27, n. 14, p. 2084-2090, 2008.

Fletcher, C. D. M., Unni, K. K. World Health Organization Classification of Tumours Pathology and Genetics of Tumours of Soft Tissue and Bone: IARC Press International Agency For Research On Cancer, 426 p. 2002.

Friedl, P., Wolf, K. Tumour-cell invasion and migration: diversity and escape mechanisms. Nature Reviews. Cancer, v. 3, n. 5, p. 362-74, 2003.

Fujimura, K., Choi, S., Wyse, M., Strnadel, J., Wright, T., Klemke, R. Eukaryotic Translation Initiation Factor 5A (EIF5A) Regulates Pancreatic Cancer Metastasis by Modulating RhoA and Rho-associated Kinase (ROCK) Protein Expression Levels. The Journal of Biological Chemistry, v. 290, n. 50, p. 29907 29919, 2015.

Fukushima M., Koizumi K., Nakajima Y., Fukuda Y., Kawamoto M., Shimizu K. Primitive Neuroectodermal Tumor/Ewing's sarcoma with Long-term Follow-up. The Japanese J Thor Card Sur, v. 53, n. 2, p. 97-101, 2005.

Ginsberg, J. P., Woo, S. Y., Johnson, M. E., Hicks, M. J., Horowitz, M. E. Ewing's Sarcoma Family of Tumors: Ewing's Sarcoma of Bone and Soft Tissue and the Peripheral Primitive Neuroectodermal Tumors. In: Pizzo, P. A., Poplack, D., G. Principles \& Practice of Pediatric Oncology: Lippincott-Raven, 4 ed., 2001.

Goodman, K. B., Cui, H., Dowdell, S. E., Gaitanopoulos, D. E., Ivy, R. L., Sehon, C. A., Stavenger, R. A., Wang, G. Z., Viet, A. Q., Xu, W., Ye, G., Semus, S. F., Evans, C., Fries, H. E., Jolivette, L. J., Kirkpatrick, R. B., Dul, E., Khandekar, S. S., Yi, T., Jung,D. K., Wright, L. L., Smith, G, K., Behm, D. J., Bentley, R., Doe, C. P., Hu, E., Lee, D. Development of Dihydropyridone Indazole Amides as Selective Rho-Kinase Inhibitors. J. Med. Chem, v. 50, p. 6-9, 2007.

Gonzalez, H. H. E., Betancourt, M.G., Martinez Q. O., Cabezas, H. I. Sarcoma de Ewing. Archivo Médico de Camaguey, v. 17, n. 5, p. 623-640, 2013.

Hall, A. Rho GTPases and the actin cytoskeleton. Science, v. 279, p. 509-514, 1998.

Hancock J.D., Lessnick S.L. A transcriptional profiling meta-analysis reveals a core EWS-FLI gene expression signature. Cell Cycle, v. 7, n. 2, p. 250-256, 2008.

Heasman, S. J., Ridley, A. J. Mammalian Rho GTPases: new insights into their functions from in vivo studies. Nature Reviews. Molecular Cell Biology, v. 9, p. 690 - 701, 2008.

Hsu, C., Chang, Z., Lee, H. Immunohistochemical evaluation of ROCK activation in invasive breast cancer. BMC Cancer, v. 15, n. 943, 2015.

Hunold, A., Weddeling, N., Paulussen, M., Ranft, A. Topotecan and Cyclophosphamide in Patients With Refractory or Relapsed Ewing Tumors, Pediatric Blood Cancer, n. 47, n. 6, p. 795-800, 2006. 
Instituto Nacional do Câncer, INCA. Disponível em:

<http://www.inca.gov.br/conteudo_view.asp?id=345>. Acesso em de março de 2016.

Izawa, I., Amano, M., Chihara, K., \& Yamamoto, T. Possible involvement of the inactivation of the Rho-Rho-kinase pathway in oncogenic Ras-induced transformation, Oncogene, v. 17, p. 2863-2871, 1998.

Izawa, I., Inagaki, M. Regulatory mechanisms and functions of intermediate filaments: a study using site- and phosphorylation state-specific antibodies. Cancer Science, v. 97, n. 3, p. 167-74, 2006.

Julian, L., Olson, M. F. Rho-associated coiled-coil containing kinases (ROCK): structure, regulation, and functions. Small GTPases, v. 5, e29846, 2014. doi: 10.4161/sgtp.29846

Kamai T, Tsujii T, Arai K, Takagi K, Asami H, Ito Y, Oshima H. Significant association of Rho/ROCK pathway with invasion and metastasis of bladder cancer. Clinical Cancer Research, v. 9, p. 26322641, 2003.

Kartsogiannis, V. \& Wah Ng, K. Cell lines and primary cell cultures in the study of bone cell biology. Molecular and Cellular Endocrinology, v. 228, p. 79-102, 2004.

Kauer M., Ban J., Kofler R., Walker B., Davis S., Meltzer P., Kovar H. A molecular function map of Ewing's sarcoma. Plos One, v. 4, n. 4, 26 p, e5415, 2009.

Kimura, K., Ito, M., Amano, M., Chihara, K., Fukata, Y., Nakafuku, M.,Kaibuchi, K. Regulation of Myosin Phosphatase by Rho and Rho-Associated Kinase (Rho-Kinase), Science, v. 273, p. 10-13, 1996.

Kroiss, A., Vincent, S., Decaussin-Petrucci, M., Meugnier, E., Viallet, J., Ruffion, A., Chalmel, F., Samarut, J., Allioli, N. Androgen-regulated microRNA-135a decreases prostate cancer cell migration and invasion through downregulating ROCK1 and ROCK2. Oncogene, v. 34, n. 22, p. $2846-2855$, 2014.

Kosako, H., Yoshida, T., Matsumura, F., Ishizaki, T. Rho-kinase / ROCK is involved in cytokinesis through the phosphorylation of myosin light chain and not ezrin / radixin / moesin proteins at the cleavage furrow, Oncogene, v. 19, p. 6059-6064, 2000.

Kovar H., Alonso J., Aman P., Aryee D.N., Ban J., Burchill S.A. The first European interdisciplinary Ewing sarcoma research summit. Front Oncology, v. 2, n. 54, 6 p., 2013.

Lane J, Martin TA, Watkins G, Mansel RE, Jiang WG. The expression and prognostic value of ROCK I and ROCK II and their role in human breast cancer. Int J Oncololy, v. 33, n. 3, p. 585-593, 2008.

Ladenstein, R., Pötschger, U., Le Deley, M. C., Whelan, J., Paulussen, M., Oberlin, O., Jürgens, H. Primary disseminated multifocal Ewing sarcoma: results of the Euro-EWING 99 trial. Journal of Clinical Oncology : Official Journal of the American Society of Clinical Oncology, v. 28. n. 20, p. 328491, 2010.

Laurence, V., Pierga, J.-Y., Barthier, S., Babinet, A., Alapetite, C., Palangié, T., Pinieux, G., Anract, P., Pouillart, P. Long-Term Follow Up of High-Dose Chemotherapy With Autologous Stem Cell Rescue in Adults With Ewing Tumor. American Journal of Clinical Oncology, v. 28, n. 3, p. 301-309, 2005.

Li, H., Peng, H., Fang, H., Tang, J., Wen, Z. Differential expression of Ang-1, Ang-1 and Tie-2 mRNA in bone tumors. Medical Journalof Wuhan University, v. 29, n. 6, p. 780-791, 2008. 
Li, Z., Wang, C., Jiao, X., Lu, Y., Fu, M., Quong, A. A., Dye, C., Yang, J., Dai, M., Ju, X., Zhang, X., Li, A., Burbelo, P., Stanley, E. R., Pestell, R. G. Cyclin D1 Regulates Cellular Migration through the Inhibition of Thrombospondin 1 and ROCK Signaling. Molecular and Cellular Biology, v. 26, n. 11, p. $4240-$ 4256, 2006.

Lin, P. P., Brody, R. I., Hamelin, A. C., Bradner, J. E., Healey, J. H., Ladanyi, M. Differential transactivation by alternative EWS-FLI1 fusion proteins correlates with clinical heterogeneity in Ewing's sarcoma. Cancer Research., v. 59, p. 1428-1432, 1999.

Lissat, A., Chao, M. M., \& Kontny, U. Targeted Therapy in Ewing Sarcoma. ISRN Oncology, 609439, 2012. doi: $10.5402 / 2012 / 609439$

Liu, S., Goldstein, R. H., Scepansky, E. M., Rosenblatt, M. Inhibition of rho-associated kinase signaling prevents breast cancer metastasis to human bone. Cancer Research, v. 69, n. 22, p. 8742-51, 2009.

Liu, X., Choy, E., Hornicek, F.J., Yang, S., Yang, C., Harmon, D., Mankin, H., Duan, Z. ROCK1 as a Potential Therapeutic Target in Osteosarcoma. Journal of Orthopaedic Research, v. 8, p. 1259-1266, 2011.

Macedo, C. R., Petrilli, A.S. Tumores ósseos malignos na criança e no adolescente. Pediatria Moderna, v. 35, n. 8, p. 600-608, 1999.

Maekawa, M., Ishizaki, T., Boku, S., Watanabe, N., Fujita, A., Iwamatsu, A., Obinata, T., Ohashi, K., Mizuno, K., Narumiya, S. Signaling from Rho to the Actin Cytoskeleton Through Protein Kinases ROCK and LIM-kinase. Science, v. 285, n. 5429, p. 895-898, 1999.

Mahlendorf, D. E., Staege, M. S. Characterization of Ewing sarcoma associated cancer / testis antigens, Cancer Biology \& Therapy, v. 14, n. 3, p. 254-261, 2013.

Manickam, N., Patel, M., Griendling, K. K., Gorin, Y., Barnes, J. L. RhoA/Rho kinase mediates TGF-1induced kidney myofibroblast activation through Poldip2/Nox4-derived reactive oxygen species. $J$ Physiol Renal Physiol, v. 307, p. F159-F171, 2014.

Marie, P. J., Fromigué, O., Modrowski, D. Deregulation of osteoblast differentiation in primary bone cancer. In: Heymann, D. Bone Cancer: Primary Bone Cancer and Bone Metastases. Elsevier, 2. ed. 2014, p. 39-49.

Matsui, T., Amano, M., Yamamoto, T., Chihara, K., Nakafuku, M., Ito, M., Kaibuchi, K. Rho-associated kinase, a novel serine / threonine kinase, as a putative target for the small GTP binding protein Rho. The EMBO Journal, v. 15, n. 9, p. 2208-2216, 1996.

Matsumura, F. Regulation of myosin II during cytokinesis in higher eukaryotes. Trends in Cell Biology, v. 15, n. 7, p. 371-7, 2005.

May W.A., Lessnick S.L., Braun B.S., Klemsz M., Lewis B.C., Lunsford L.B., Hromas R., Denny C.T. The Ewing's sarcoma EWS/FLI-1 fusion gene encodes a more potent transcriptional activator and is a more pow- erful transforming gene than FLI-1. Mol Cell Biol, v. 13, p. 7393-7398, 1993.

Mertsch, S., Thanos, S. Opposing Signaling of ROCK1 and ROCK2 Determines the Switching of Substrate Specificity and the Mode of Migration of Glioblastoma Cells. Molecular Neurobioly, v. 49, p. 900-915, 2014. 
Montenegro, C. F. Efeitos de uma Desintegrina RGD Recombinate de Rhinocerophis alternatus (Bothrops alternatus) na migração de células normais e tumorais. Universidade Federal de São Carlos (Dissertação de Mestrado), 69 p., 2011.

Morgan-Fisher M, Wewer UM, Yoneda A. Regulation of ROCK activity in cancer. J Histochem Cytochem. v. 61, n. 3, p. 185-98, 2013.

Nakagawa, O., Fujisawa, K., Ishizaki, T., Saito, Y., Nakao, K. ROCK-I and ROCK-II, two isoforms of Rhoassociated coiled-coil forming protein serine/threonine kinase in mice. FEBS Letters, n. 392, 189-193, 1996.

Narumiya S, Tanji M, Ishizaki T. Rho signaling, ROCK and mDia1, in transformation, metastasis and invasion. Cancer Metastasis Rev. v. 28, p. 65-76, 2009.

Ohashi, K. Nagata, K., Maekawa, M., Ishizaki, T., Narumiya, S., Mizuno, K. Rho-associated Kinase ROCK Activates LIM-kinase 1 by Phosphorylation at Threonine 508 within the Activation Loop. Journal of Biological Chemistry, v. 275, n. 5, p. 3577-3582, 2000.

Olson, M. F. Applications for ROCK kinase inhibition. Curr Opin Cell Biol, v. 20, n. 2, p. 242-248, 2008.

Oppel, F., Müller, N., Schackert, G., Hendruschk, S., Martin, D., Geiger, K. D., Temme, A. SOX2-RNAi attenuates S-phase entry and induces RhoA-dependent switch to protease-independent amoeboid migration in human glioma cells. Molecular Cancer, v. 10, n. 137, 2011.

Pan, P., Shen, M., Yu, H., Li, Y., Li, D., Hou, T. Advances in the development of Rho-associated protein kinase (ROCK) inhibitors. Drug Discovery Today, v. 18, n. 23-24, p. 1323-33, 2013.

Patel, R. A., Liu, Y., Wang, B., Li, R., Sebti, S. M. Identification of novel ROCK inhibitors with antimigratory and anti-invasive activities. Oncogene, v. 33, n. 5, p. 550-555, 2014.

Pawlak, G., Helfman, D. M. Post-transcriptional Down-regulation of ROCKI / Rho- kinase through an MEK-dependent Pathway Leads to Cytoskeleton Disruption in Ras-transformed Fibroblasts, Molecular Biology of the Cell, v. 13, p. 336-347, 2002.

Pei, X., Mo, Y., Ning, B., Yuan, Z., Peng, L., Ma, R. The role of TGFb1 stimulating ROCK I signal pathway to reorganize actin in a rat experimental model of developmental dysplasia of the hip. Mol Cell Biochem, v. 391, p. 1-9, 2014.

Peter M., Couturier J., Pacquement H., Michon J., Thomas G., Magdelenat H., Delattre O. A new member of the ETS family fused to EWS in Ewing tumors. Oncogene, v. 14, p. 1159-1164, 1997.

Pinheiro, N. M. (2010). Papel Funcional das GTPases Rho na Proliferação e Diferenciação Celular em Carcinoma Epidermóide Oral. Universidade Federal do Triângulo Mineiro (Dissertação de Mestrado), $109 \mathrm{p.}$

Reymond, N., Im, J. H., Garg, R., Cox, S., Soyer, M., Riou, P., Colomba, A., Muschel, R. J., Ridley, A. J. RhoC and ROCKs regulate câncer cell interactions with endothelial cells. Molecular Oncology, v. 9, n. 6, p. 1043-1055, 2015.

Riggi, N., Suva, M., Vito, C., Provero, P., Stehle, J., Baumer, K., Cironi, L., Janiszewska, M., Petricevic, T., Suva, D., Tercier, S., Joseph, J., Guillou, L., Stamenkovic, I. EWS-FLI-1 modulates miRNA145 and SOX2 expression to initiate mesenchymal stem cell reprogramming toward Ewing sarcoma cancer stem cells. Genes \& Development, v. 24, p. 916-932, 2010. 
Riggi, N., Knoechel, B., Gillespie, S. M., Rheinbay, E., Boulay, G., Suvà, M. L., Rossetti, N. E., Boonseng, W. E., Oksuz, O., Cook, E. B., Formey, A., Patel, A., Gymrek, M., Thapar, V., Deshpande, V., Ting, D. T., Hornicek, F. J., Nielsen, G. P., Stamenkovic, I., Aryee, M. J., Bernstein, B. E., Rivera, M. N. EWS-FLI1 utilizes divergent chromatin remodeling mechanisms to directly activate or repress enhancer elements in Ewing sarcoma. Cancer Cell, v. 26, n, 5, p. 668 - 681, 2014.

Sahai, E. \& Marshall, C.J. Differing modes of tumour cell invasion have distinct requirements for Rho/ROCK signalling and extracellular proteolysis. Nature Cell Biology, v. 5, n. 8, p. 711-719, 2003.

Samuel, M. S., Lopez, J. I., McGhee, E. J., Croft, D. R., Strachan, D., Timpson, P., Olson, M. F. Actomyosin-mediated cellular tension drives increased tissue stiffness and $\beta$-catenin activation to induce epidermal hyperplasia and tumor growth. Cancer Cell, v. 19, n. 6, p. 776-91, 2011.

Sand, L. G. L., Szuhai, K., Hogendoorn, P. C. W. Sequencing Overview of Ewing Sarcoma: A Journey across Genomic, Epigenomic and Transcriptomic Landscapes. International Journal of Molecular Science, v. 16, p. 16176-16215, 2015.

Sandberg, A., Bridge, J. Updates on cytogenetics and molecular genetics of bone and soft tissue tumors: Ewing sarcoma and peripheral primitive neuroectodermal tumors. Cancer Genetics and Cytogenetics, v. 123, n. 1, p. 1-26, 2000.

Sandberg, A., Bridge, J. Updates on the cytogenetics and molecular genetics of bone and soft tissue tumors: osteosarcoma and related tumors. Cancer Genetics and Cytogenetics, v. 145, n. 1, p. 1-30, 2003.

Sarver, A. E., Sarver, A. L., Thayanithy, V., Subramanian, S. Identification, by systematic RNA sequencing, of novel candidate biomarkers and therapeutic targets in human soft tissue tumors. Laboratory Investigation, v. 95, p. 1077-1088, 2015.

Schaefer K.L., Eisenacher M., Braun Y., Brachwitz K., Wai D.H., Dirksen U., Lanvers-Kaminsky C., Juergens H., Herrero D., Stegmaier S., Koscielniak E., Eggert A., Nathrath M., Gosheger G., Schneider D.T., Bury C., Diallo-Danebrock R., Ottaviano L., Gabbert H.E., Poremba C.. Microarray analysis of Ewing's sarcoma family of tumours reveals characteristic gene expression signatures associated with metastasis and resistance to chemotherapy. European Journal of Cancer, v. 44, v. 5, p. 699-709, 2008.

Schmidt, S., Friedl, P. (2010). Interstitial cell migration: integrin-dependent and alternative adhesion mechanisms. Cell and Tissue Research, v. 339, n. 1, p. 83-92, 2010.

Schofield, A. V, Bernard, O. Rho-associated coiled-coil kinase (ROCK) signaling and disease. Critical Reviews in Biochemistry and Molecular Biology, v. 48, n. 4, p. 301-16, 2013.

Shi, J., Surma, M., Zhang, L., Wei, L. Dissecting the roles of ROCK isoforms in stress-induced cell detachment. Cell Cycle, v. 12, n. 10, p. 1492-1500, 2013.

Schroeder, A., Heller, D. A., Winslow, M. M., Dahlman, J. E., Pratt, G. W., Langer, R., Jacks, T., Anderson, D. G. The steps of metastasis and opportunities for therapeutic intervention. Nature Reviews Cancer, v. 12, p. 39-50, 2012.

Sun, K., Duan, X., Cai, H., Liu, X., Yang, Y., Li, M., Zhang, X., Wang, J. Curcumin inhibits LPA-induced invasion by attenuating RhoA/ROCK/MMPs pathway in MCF7 breast cancer cells. CLin Exp Med, v. 16, v. 1, p. $37-47,2015$. 
Tanaka, K., Iwakuma, T., Harimaya, K., Sato, H., Iwamoto, Y. EWS-Fli1 antisense oligodeoxynucleotide inhibits proliferation of human Ewing's sarcoma and primitive neuroectodermal tumor cells. J. Clin. Invest, v. 99, p. 239-247, 1997.

Tilson, S. G., Haley, E. M., Triantafillu, U. L., Dozier, D. A., Langford, C. P., Gillespie, G. Y., Kim, Y. ROCK Inhibition Facilitates In Vitro Expansion of Glioblastoma Stem-Like Cells. Plos One, v. 10, n. 7, e0132823, 2015.

Tselioua, M., Al-Qahtanib, A., Alarific, S., Alkahtanic, S. H., Stournarasd, C., Sourvinosa, G. The Role of RhoA, RhoB and RhoC GTPases in Cell Morphology, Proliferation and Migration in Human Cytomegalovirus (HCMV) Infected Glioblastoma Cells. Cellular Physiology and Biochemistry, v. 38, p. $94-109,2016$.

Tsugita, M., Yamada, N., Noguchi, S., Yamada, K., Moritake, H., Shimizu, K., Akao, Y., Ohno, T. Ewing Sarcoma Cells Secrete EWS/Fli-1 Fusion mRNA via Microvesicles. Plos One, v. 8, n. 10, e77416, 2013.

Turc-Carel C., Aurias A., Mugneret F. Lizard S., Sidaner I., Volk C., Thiery J.P., Olschwang S., Philip I., Berger M.P. Chromosomes in Ewing's sarcoma. I. An evaluation of 85 cases of remarkable consistency of t(11;22) (q24;q12). Cancer Genet Cytogenet, n. 32, p. 229-238, 1988.

Valen, F. V, Fulda, S., Schafer, K., Truckenbrod, B., Hotfilder, M., Poremba, C., Debatin, K., Winkelmann, W. Selective and Nonselective toxicity of TRAIL/Apo2L combined with chemotherapy in human bone tumour cells vs. normal human cells. Int. J. Cancer, v. 107, p. 929-940, 2003.

Wang, J., Sun, L., Yang, M., Luo, W., Gao, Y., Liu, Z., Qiu, X. DEK depletion negatively regulates Rho/ROCK/MLC pathway in non-small cell lung cancer. Journal of Histochemistry \& Cytochemistry, v. 61, n. 7, p. 510-521, 2013.

Wei, L., Malhotra, S. V. Recent Development of Cyclic Amide (Pyridone/Lactam) Moiety Containing Heterocycles as Protein Kinase Inhibitors. Current Medicinal Chemistry, v. 17, p. 234-253, 2010.

Wei, L.; Surma, M.; Shi, S. Novel Insights into the Roles of Rho Kinase in Cancer. Archivum Immunologiae et Therapiae Experimentalis, 2016. DOI: 10.1007/s00005-015-0382-6

West, D. C. Ewing sarcoma family of tumors. Current Opinion in Oncology, v. 12, p. 323-329, 2000.

Ying, G.U., Zhang, Y. Expression and significance of RhoA and ROCK2 in cervical intraepithelial neoplasia and cervical câncer. Acta Universitatis Medicinalis Nanjing (Natural Science), v. 3, 2012.

Yong-jun, W.U., Yi, T.A.N.G., Zhen-feng, L.I., Yi, Z.H.A.O., Zhen-jiang, W.U., Qi, S.U. Expression and significance of Rac1, Pak1 and ROCK1 in gastric carcinoma. Asia-pacific Journal of Clincal Oncology, v. 10, p. 33-39, 2014.

Zhang, J., Li, X., Wang, Y., Zhang, Q., Gu, S., Wu, X., Zhu, G., Li, Q., Liu, G. ROCK Is Involved in Vasculogenic Mimicry Formation in Hepatocellular Carcinoma Cell Line. Plos One, v. 9, n. 9, e107661, 2014.

Zhang, J., He, X., Ma Y., Liu, Y., Shi, H., Guo, W.,Liu, L. Overexpression of ROCK1 and ROCK2 inhibits human laryngeal squamous cell carcinoma, Int J Clin Exp Pathol , v. 8, n. 1, p. 244-251, 2015.

Zhou, Z., Zhou, R., Guan, H., Bucana, C. D., Kleinerman, E. S. E1A gene therapy inhibits angiogenesis in a Ewing's sarcoma animal model. Molecular Cancer Therapeutics, v. 2, p. 1313-19, 2003. 
- Apêndices 
Apêndice A: Resumo das expressões dos genes ROCK1 e ROCK2 em amostras de ossos não neoplásicos, linhagens primárias de osteoblasto, amostras de SE e linhagens celulares de SE.

\begin{tabular}{|c|c|c|c|c|c|c|}
\hline Grupos & Genes & $\mathbf{n}$ & Média & $\begin{array}{c}\text { Desvio } \\
\text { Padrão }\end{array}$ & Mínima & Máxima \\
\hline \multirow{2}{*}{ Amostras tumorais de SE } & ROCK1 & 18 & 0,58 & 0,24 & 0,29 & 1,05 \\
\cline { 2 - 7 } & ROCK2 & 18 & 0,86 & 0,81 & 0,1 & 2,74 \\
\hline \multirow{2}{*}{ Linhagens celulares de SE } & ROCK1 & 2 & 0,41 & 0,14 & 0,31 & 0,52 \\
\cline { 2 - 7 } & ROCK2 & 2 & 2,26 & 0,01 & 2,25 & 2,27 \\
\hline \multirow{2}{*}{ Osso não neoplásico } & ROCK1 & 8 & 1,26 & 0,59 & 0,39 & 2,17 \\
\cline { 2 - 7 } & ROCK2 & 8 & 2,6 & 1,58 & 0,88 & 4,82 \\
\hline \multirow{2}{*}{ Linhagem de osteoblasto } & ROCK1 & 9 & 1,01 & 0,45 & 0,56 & 1,98 \\
\cline { 2 - 7 } & ROCK2 & 9 & 1,52 & 0,27 & 1,13 & 1,86 \\
\hline
\end{tabular}

